\title{
Olig1 Acetylation and Nuclear Export Mediate Oligodendrocyte Development
}

\author{
Jinxiang Dai, ${ }^{1}$ Kathryn K. Bercury, ${ }^{1}$ Weilin Jin, ${ }^{2,3}$ and Wendy B. Macklin ${ }^{1}$ \\ ${ }^{1}$ Department of Cell and Developmental Biology, University of Colorado School of Medicine, Aurora, Colorado 80045, ${ }^{2}$ Institute of Bio-Nano-Science and \\ Engineering, Department of Instrument Science and Engineering, School of Electronic Information and Electrical Engineering, and ${ }^{3}$ School of Life Sciences \\ and Biotechnology, Shanghai Jiao Tong University, Shanghai 200240, China
}

The oligodendrocyte transcription factor Olig1 is critical for both oligodendrocyte development and remyelination in mice. Nuclear to cytoplasmic translocation of Olig1 protein occurs during brain development and in multiple sclerosis, but the detailed molecular mechanism of this translocation remains elusive. Here, we report that Olig1 acetylation and deacetylation drive its active translocation between the nucleus and the cytoplasm in both mouse and rat oligodendrocytes. We identified three functional nuclear export sequences (NES) localized in the basic helix-loop-helix domain and one specific acetylation site at Lys 150 (human Olig1) in NES1. Olig1 acetylation and deacetylation are regulated by the acetyltransferase CREB-binding protein and the histone deacetylases HDAC1, HDAC3, and HDAC10. Acetylation of Olig1 decreased its chromatin association, increased its interaction with inhibitor of DNA binding 2 and facilitated its retention in the cytoplasm of mature oligodendrocytes. These studies establish that acetylation of Olig1 regulates its chromatin dissociation and subsequent translocation to the cytoplasm and is required for its function in oligodendrocyte maturation.

Key words: acetylation; nuclear export; Olig1

\section{Significance Statement}

The nuclear to cytoplasmic translocation of Olig1 protein has been observed during mouse and human brain development and in multiple sclerosis in several studies, but the detailed molecular mechanism of this translocation remains elusive. Here, we provide insight into the mechanism by which acetylation of Olig1 regulates its unique nuclear-cytoplasmic shuttling during oligodendrocyte development and how the acetylation status of Olig1 modulates its distinct function in the nucleus versus the cytoplasm. The current study provides a unique example of a lineage-specific transcription factor that is actively translocated from the nucleus to the cytoplasm as the cell differentiates. Importantly, we demonstrate that this process is tightly controlled by acetylation at a single lysine.

\section{Introduction}

Myelin ensheathment of axons provides valuable trophic support to axons and it is physiologically critical to increase electrical conduction dramatically (Bullock et al., 1984). Human demyelinating diseases in the CNS, such as multiple sclerosis (MS), result in oligodendrocyte cell death, axonal degeneration, and cognitive

\footnotetext{
Received March 6, 2015; revised Sept. 30, 2015; accepted 0ct. 25, 2015.

Author contributions: J.D. designed research; J.D. performed research; W.J. contributed unpublished reagents/ analytic tools; J.D. analyzed data; J.D., K.K.B., and W.B.M. wrote the paper.

This work was supported by the NIH (Grant NS08223 to W.B.M.) and by the National Natural Science Foundation of China (Grant 31171033 to W.J.). We thank Katherine E. Saul and Hilary Sachs for technical assistance, and Dr. Danielle Harlow and Dr. Marnie Preston for helpful discussion.

The authors declare no competing financial interests.

Correspondence should be addressed to Dr. Wendy B. Macklin, Department of Cell and Developmental Biology, University of Colorado School of Medicine, 12800 East $17^{\text {th }}$ Ave, Building RC1S, Room L18-12403B, Aurora, CO 80045. E-mail:Wendy.Macklin@ucdenver.edu.

DOI:10.1523/JNEUROSCI.0882-15.2015

Copyright $\odot 2015$ the authors $\quad 0270-6474 / 15 / 3515875-19 \$ 15.00 / 0$
}

and motor deficits (Trapp and Nave, 2008; Franklin and ffrenchConstant, 2008). Oligodendrocyte progenitor cells (OPCs) are present in MS lesions, suggesting that demyelinated lesions should be able to remyelinate (Chang et al., 2000). Nevertheless, only minimal remyelination occurs and it appears that OPC maturation is particularly vulnerable in MS (Wolswijk, 1998, 2000; Chang et al., 2002; Kuhlmann et al., 2008). The molecular mechanisms of oligodendrocyte differentiation and myelination during development and after demyelination are being actively investigated and the current studies address one element of this program.

Two closely related basic helix-loop-helix (bHLH) transcription factors, Olig1 and Olig2, function in the well established transcriptional regulatory network of oligodendrocyte lineage progression (Emery, 2010a,b) and are critical for oligodendrocyte specification and differentiation (Lu et al., 2002; Zhou and Anderson, 2002; Mei et al., 2013). However, the function of Olig1 during oligodendrocyte development has been unclear, with dif- 
fering evidence based on the generation of different Olig1-null lines (Lu et al., 2002; Xin et al., 2005; Paes de Faria et al., 2014). Our recent analysis of brain development in Olig1-null mice reveals an essential role for Olig1 in OPC differentiation in brain, but less so in spinal cord (Dai et al., 2015).The current studies focus on elements of the regulation of Olig1 function in oligodendrocyte development in brain.

Subcellular translocation of Olig1 during both oligodendrocyte development and remyelination is unique to Olig1 relative to Olig2, which is only found in the nucleus. Olig1 is present in OPC nuclei and translocates progressively to the cytoplasm as oligodendrocytes mature in the developing mouse and human brain (Arnett et al., 2004; Jakovcevski and Zecevic, 2005; Kitada and Rowitch, 2006; Niu et al., 2012). Interestingly, during remyelination, Olig1 relocates back to the nucleus, suggesting a nuclear function for Olig1 that appears essential for remyelination (Arnett et al., 2004). The mechanism regulating this intriguing Olig1 translocation has not been established. Posttranslational modification of proteins, particularly phosphorylation and acetylation, regulates the subcellular location of several transcription factors (Krämer et al., 2009; Meek and Anderson, 2009) and a recent in vitro study indicates that Olig1 phosphorylation at Ser149 (Ser138, mouse Olig1) can regulate its cytoplasmic location and cell membrane extension (Niu et al., 2012).

In the current study, we focused on the role of acetylation in regulating Olig1 localization. We established that Olig1 is acetylated by CREB-binding protein (CBP) on lysine150 (Lys139, mouse Olig1) as oligodendrocytes mature both in vitro and in vivo. Acetylation of Olig1 increased its binding with inhibitor of DNA binding 2 (Id2), decreased its association with chromatin, and facilitated its nuclear to cytoplasmic relocation during oligodendrocyte development. Our data show that Olig1 acetylation is important for its function in promoting oligodendrocyte lineage progression and morphological differentiation and reveal the mechanism by which its acetylation regulates its nuclear to cytoplasmic translocation.

\section{Materials and Methods}

Animal procedures and primary cell culture. All animal procedures were conducted in accordance with the University of Colorado Institutional Animal Care and Use Committee and the National Institutes of Health guidelines for the care and use of laboratory animals. Mouse neural progenitor cells were isolated from neocortex of male and female embryonic day 12.5 (E12.5) to E14.5 embryos of wild-type C57BL/6J or Olig1-null mice [B6;129S4-Olig1tm1(cre)Rth/J strain; Jackson Laboratories, cata$\log \# 011105]$ and converted to OPCs as described previously (Pedraza et al., 2008). Mixed glial cultures were generated from male and female postnatal day 0 (P0) to 3-d-old Sprague Dawley rat pups, as described previously (Dai et al., 2014).

Plasmid vectors. The open reading frame of human Olig1 was amplified from a human embryonic cDNA library (Origene) and subcloned into pCMV-myc vector (Clontech), pEGFP-N1/C3 vectors (Clontech), pGEX-KG vector (for GST tag protein purification), and HA-TAT vector (a gift from Dr. Steven Dowdy, University of California, for TAT tag fusion protein purification). The Olig1 and Olig2 mutant vectors used in this study were generated using Stratagene's QuikChange Site-Directed Mutagenesis Kit (Agilent Technologies) following the manufacturer's protocol (detailed primers and PCR conditions provided upon request). The p300-myc and p300DY-myc vectors were kindly provided by Dr. Tso-Pang Yao (Duke University). The pEGFPC1-mId2 and pEGFPC1mId4 vectors described previously (Kurooka and Yokota, 2005) were kind gifts from Dr. Hisanori Kurooka (University of Fukui, Japan). The HA-tagged human HDAC1, HDAC 2, HDAC3, HDAC4, HDAC5, HDAC6, HDAC7, HDAC8, and HDAC10 vectors were from Drs. Minoru Yoshida and Akihisa Matsuyama (Chemical Genetics Laboratory,
RIKEN, Japan).The Flag-Sirtuin1/2 vectors were from Dr. Eric Verdin (University of California). The pCMV5-Sox10 vector was kindly provided by Dr. Michael Wegner (Lehrstuhl für Biochemie und Pathobiochemie, Germany). The following vectors were obtained from Addgene: pRc/RSV-m CBP-HA (catalog \#16701), pAdEasy Flag GCN5 (catalog \#14106), pAd-Track Flag GCN5 Y621A/P622A (catalog \#14425), pCIflag-PCAF (catalog \#8941), p3xFLAG-mE47 (catalog \#34585), and FlaghCRM1 (catalog \#17647). The GCN5 and GCN5-Y621A/P622A cDNA were digested with KpnI and XhoI and subcloned into pcDNA3.1+ vector (Life Technologies). CBP shRNA was constructed by Genepharma into a lentivirus expression vector pGLVH1/GFP+Puro using the sequence $5^{\prime}$-gcagcagccagcattgata- $3^{\prime}$ and $5^{\prime}$-ctgatgagctgatacccaatg- $3^{\prime}$.

Antibodies. Two rabbit anti-mouse Olig1 antibodies targeting different regions were generated by Abgent. The sequences of immunizing peptides were SLLPKPAREKAEAP (residue 55-68 of mOlig1, rabbit anti-Olig1-1) and TKYLSLALDEPPC (residue 206-218, rabbit antiOlig1-2). The specificity of these two antibodies was validated by Western blot, immunoprecipitation, and immunocytochemistry (data not shown). Based on their performance, the Olig1-1 antibody was used for Western blots and Olig1-2 antibodies were used for immunoprecipitation studies. The K150 acetylation-site-specific antibody of Olig1, which is conserved among human, mouse, and rat Olig1 proteins, was generated against the modified peptide GAPGRKLS[Ac] KIAT (residues 142153 of human Olig1/131-142 of mouse Olig1) by Abgent. The S149 phosphorylation-site-specific antibody of Olig1, which is conserved among human, mouse, and rat Olig1 proteins, was generated against the modified peptide GAPGRKL[pSer]KIAT (residues 142-153 of human Olig1/131-142 of mouse Olig1) by Abgent. The antiserum was first absorbed on a column containing nonacetylated or nonphosphorylated peptide and then affinity purified on an acetylpeptide or phosphopeptide column, respectively. The purified acetyl-Olig1 antibody and phosphoOlig1 antibody were validated and used at 1:250 for Western blot.

Primary antibodies used for Western blot, immunoprecipitation, or immunofluorescence were as follows: rabbit anti-Olig2 and Olig1 (a gift from Dr. Charles Stiles, Harvard University); mouse anti-Olig1 (Millipore, catalog \#MAB5540); the following antibodies were purchased from Santa Cruz Biotechnology: mouse anti-Olig1 (sc-166257); rabbit antiId2 (sc-489); rabbit anti-CBP (sc-369); rabbit anti-p300 (sc-584); goat anti-Sox10 (sc17342); rabbit anti-Sox10 (Sigma-Aldrich, catalog \#S8193); mouse anti- $\beta$-tubulin (Sigma-Aldrich, catalog \#T8328); mouse anti-CC1 antibody (Calbiochem, catalog \#OP80); rat anti-PDGFR $\alpha$ (BD PharMingen, catalog \#55874); O4 hybridoma (gift from Dr. Rashmi Bansal, University of Connecticut Health Sciences Center); mouse antimyelin basic protein (MBP; Covance, catalog \#SMI-94); mouse anti-Flag M2 (Sigma-Aldrich, catalog \#F3165); anti-Flag M2 affinity gel (SigmaAldrich, catalog \#A2220); mouse anti-myc (9E10) supernatant (Developmental Studies Hybridoma Bank). The following antibodies were obtained from Cell Signaling Technology: rabbit anti-Id2 (catalog \#3431); rabbit anti-CBP (catalog \#7389); rabbit anti-GCN5 (catalog \#3305); rabbit anti-GAPDH (catalog \#2118); rabbit anti-LaminA/C (catalog \#2032,); rabbit anti-acetylated lysine (catalog \#9814); mouse antiacetylated lysine (catalog \#9681); rabbit anti-Histone H3 (catalog \#4620); acetyl-histone $\mathrm{H} 3$ antibody sampler kit (catalog \#9927); and mouse antiGFP (catalog \#2955).

Cell line culture and transfection. HEK293T cells were cultured in DMEM high glucose (Life Technologies) supplemented with 10\% (v/v) fetal bovine serum at $37^{\circ} \mathrm{C}$ with $5 \%(\mathrm{v} / \mathrm{v}) \mathrm{CO}_{2}$. Plasmid transfection was performed using either Lipofectamine LTX and Plus reagent (Invitrogen, catalog \#15338; if using three plasmids or more) or LipoD 293 DNA transfection reagent (SignaGen, catalog \# SL100668; if using two plasmids or fewer) according to manufacturer's instructions. Total DNA concentrations were normalized with empty vector DNA when required. All of the biochemistry analyses of protein overexpression were done in the HEK293T cells.

OPC transfections. Rat OPCs were collected after shaking and $5 \times 10^{6}$ cells were electroporated (Amaxa nucleofection apparatus) in $100 \mu \mathrm{l}$ of nucleofection solution (Amaxa basic glial cells nucleofector kit \#VPI1006, Lonza) with Olig1 siRNAs (catalog \#L100044-01, $10 \mu \mathrm{l}$ of $20 \mu \mathrm{M}$ ) or siControl nontargeting siRNA pool (catalog \#B002000-UB) from 
Dharmacon. After electroporation, cells were resuspended and seeded onto poly-D-lysine/Laminin (Sigma-Aldrich, catalog \#I6758)-coated dishes or round, $12 \mathrm{~mm}$ coverslips in DMEM supplemented with N2 (Life Technologies, catalog \#17502-048), fibroblast growth factor (FGF, $10 \mathrm{ng} / \mathrm{ml}$ ), and platelet-derived growth factor (PDGF, $10 \mathrm{ng} / \mathrm{ml}$ ), and allowed to recover for $24 \mathrm{~h}$. The expression constructs ( $2 \mu \mathrm{g}$ of each well of 24 well plate) were transfected into cultured OPCs using Xfect transfection reagent (Clontech, catalog \#631318) according to the manufacturer's instructions.

Expression and purification of recombinant TAT and GST fusion proteins. Plasmids for TAT-HA or GST fusion proteins were transformed into the Escherichia coli strain BL21 (DE3). Protein production was induced with $100 \mu \mathrm{M}$ isopropyl $\beta$-D-1-thiogalactopyranoside (SigmaAldrich, catalog \#I6758) at $16^{\circ} \mathrm{C}$ for $18 \mathrm{~h}$, and protein was purified by TALON Metal Affinity Resin (Clontech, catalog \#635501) as described previously (Mi et al., 2012) or Glutathione-Superflow Resin (Clontech, catalog \#635607), respectively. The size and purity of all of the proteins were confirmed by Western blot using tag-specific and Olig1-specific antibodies. Apparent degradation of Olig1 protein was noticed under different purification conditions, likely because Olig1 protein is relatively unstable (unpublished observation). After dialysis and filtration, proteins were aliquoted and stored at $-80^{\circ} \mathrm{C}$.

In vitro histone acetyl transferase assay. Recombinant GST-tagged human histone acetyl transferase (HAT) proteins were purchased from SignalChem: CBP (catalog \#C07-31G, p300), E1A-binding protein (300 kDa; catalog \#P07-31G), and GCN5 (KAT2; catalog \#K311-381G). Their HAT activity was validated using histone $\mathrm{H} 31-21$ aa peptide as a substrate (data not shown). To perform the in vitro HAT peptide assay, varying amounts $(0.1 \mathrm{ng}$ to $1 \mu \mathrm{g})$ of nonacetylated peptide (GAPGRKLSKIAT; Abgent) were incubated with recombinant HATs (CBP, $500 \mathrm{ng}$; p300, $500 \mathrm{ng}$; GCN5, $200 \mathrm{ng}$ ) or $200 \mathrm{ng}$ glutathione S-transferase (GST) in $20 \mu \mathrm{l}$ of acetyltransferase assay buffer $(250 \mathrm{~mm}$ Tris- $\mathrm{HCl}, \mathrm{pH}$ 8.0, 0.5 mM EDTA, and $2 \mathrm{~mm}$ dithiothreitol), with $100 \mu \mathrm{M}$ acetyl-CoA (Sigma-Aldrich, catalog \#A2506) at room temperature (RT) for $1 \mathrm{~h}$. The reactions were spotted on PVDF membrane to detect acetylation of Olig1 peptides with acetyl-K150-Olig1 antibody. To perform the acetylation assay on Olig1 protein, $40 \mathrm{pmol}$ of purified Olig1-GST, Olig1-K150R-GST protein was incubated with recombinant HATs (CBP, $500 \mathrm{ng}$; p300, $500 \mathrm{ng}$; GCN5, $200 \mathrm{ng}$ ) in $40 \mu \mathrm{l}$ of acetyltransferase assay buffer at RT for $1 \mathrm{~h}$. The reactions were stopped by adding $5 \times$ Laemmli buffer and boiling for $5 \mathrm{~min}$. The reaction product was analyzed by Western blot and the acetylation of Olig1 protein was detected by either general acetyl-lysine antibody or acetyl-K150-Olig1 antibody.

Western blots and immunoprecipitation. After transfection or treatment, cultured cells or brain tissue were lysed in RIPA buffer $(25 \mathrm{~mm}$ Tris-HCl, pH 7.5, 150 mм NaCl; 1 mм EDTA, 1\% NP-40, 0.1\% DOC, $0.1 \%$ SDS) supplemented with complete mini-protease inhibitor mixture (Roche Applied Science) and phosphatase inhibitor mixture set II (CalbioChem, catalog \#564652). Samples were analyzed by Western blot and protein bands were detected with the LICOR Odyssey infrared scanner. Protein expression levels in scanned images were quantified using the Odyssey Scanner Software version 2.0. For immunoprecipitations, primary antibodies or control mouse IgG (Invitrogen, catalog \#10400C) or rabbit IgG (Invitrogen, catalog \#10500C) were incubated with protein A/G agarose (Pierce, catalog \#20421) or Dynabeads protein A or G (Invitrogen, catalog \#10004D) overnight. Antibodies were then cross-linked to beads using the Pierce immunoprecipitation kit (catalog \#26147) following the manufacturer's instructions. Cell lysates were precleared by incubation with IgG beads for $2 \mathrm{~h}$; antibody-crosslinked beads were then added and samples incubated overnight at $4^{\circ} \mathrm{C}$ while rotating. Beads were washed 3 times in RIPA buffer wash, resuspended in $30 \mu \mathrm{l}$ of SDS gel sample buffer, boiled for $5 \mathrm{~min}$, and subjected to SDS-PAGE, followed by Western blot.

Immunohistochemistry and immunocytochemistry. Immunohistochemistry was performed as described previously (Trapp et al., 1997). Freefloating cortex sections $(30 \mu \mathrm{m})$ were analyzed, with antigen retrieval in $10 \mathrm{~mm}$ sodium citrate, $\mathrm{pH} 6.0$, at $65^{\circ} \mathrm{C}$ for $10 \mathrm{~min}$ as needed, using a Pelco Biowave Pro tissue processor (Ted Pella). For immunocytochemistry, oligodendrocytes were cultured on coverslips and fixed with $4 \%$ parafor- maldehyde for $15 \mathrm{~min}$ at RT. Cells were permeabilized with $0.1 \%$ Triton X-100 for $10 \mathrm{~min}$, blocked with 3\% BSA in PBS for $60 \mathrm{~min}$ at RT, and incubated with primary antibodies overnight at $4^{\circ} \mathrm{C}$. For detection of $\mathrm{O} 4$ cell surface antigens, $\mathrm{O} 4$ antibody was diluted with medium and incubated with live cells on coverslips for $1 \mathrm{~h}$ before fixation.

Images were taken on a Zeiss Axio Imager M2 or Leica SP5 confocal microscopy. A total of six microscopic fields per coverslip from two coverslips per condition were sampled in each experiment. The covered area of $\mathrm{O}^{+}$cells was analyzed with Imaris surfaces module (Bitplane).

Subcellular fractionation. Subcellular fractionation of cells was performed as described previously (MacDonald et al., 2004). Cultured cells or brain tissue were suspended in hypotonic buffer (10 mM HEPES 7.9, $10 \mathrm{~mm} \mathrm{KCl}, 2 \mathrm{~mm} \mathrm{MgCl}, 0.5 \% \mathrm{NP} 40$, and $1 \mathrm{~mm}$ dithiothreitol with protease and phosphatase inhibitors). The cells were incubated on ice for $5 \mathrm{~min}$ and cytoplasmic and nuclear fractions were harvested by centrifugation at $1500 \times g$ for $5 \mathrm{~min}$. The isolated nuclei were then washed in hypotonic buffer, lysed in hypotonic buffer plus $500 \mathrm{~mm} \mathrm{NaCl}$, and incubated on ice for $30 \mathrm{~min}$. The nuclear fraction was used for immunoprecipitations or Western blots or subsequent subnuclear fractionation was performed as described previously (Niida et al., 2007). The isolated nuclei were then washed in hypotonic buffer, lysed in chromatin extraction buffer (3 mM EDTA, 0.2 mM EGTA, 1 mm DTT), and incubated on ice for $30 \mathrm{~min}$. The soluble nuclear and chromatin fractions were harvested by centrifugation at $1500 \times g$ for $15 \mathrm{~min}$. The isolated chromatin was then washed in chromatin extraction buffer, centrifuged at $10,000 \times$ $g$ for $1 \mathrm{~min}$, resuspended in Laemmli sample buffer, and boiled for $5 \mathrm{~min}$.

DNA pulldown assay. DNA pulldown assays were performed as described previously (Bujalka et al., 2013) with slight modifications. Briefly, the nuclear fraction was collected as described above, lysates were clarified by centrifugation at $15,000 \times g$ for $20 \mathrm{~min}$ at $4^{\circ} \mathrm{C}$, and adjusted to a total protein concentration of $1 \mu \mathrm{g} / \mu \mathrm{l}$ using buffer $\mathrm{H}(100 \mathrm{~mm} \mathrm{KCl}, 200$ mм HEPES, pH 7.8, 20\% glycerol, 1 mм DTT, 0.1\% NP40). Five micrograms of biotinylated, annealed oligonucleotides (5'-BioTEG-AACA GCTGTGAACAGCTGTGAACAGCTGTGAACAGCTGTGAACAGCT GTGAACAGCTGTG-3') were conjugated to Steptavidin magnetic beads (Roche, catalog \#11636502103) following the manufacturer's instructions. The oligonucleotide-conjugated beads were washed twice with $500 \mu \mathrm{l}$ buffer $\mathrm{H}$ and added to the cell lysate in the presence of $2 \mu \mathrm{g}$ poly (dIdC; Sigma-Aldrich, catalog \#4929). Beads were incubated with cell lysates overnight at $4^{\circ} \mathrm{C}$ with rotation and then washed three times in $500 \mu \mathrm{l}$ of buffer $\mathrm{H}$. Bound protein was eluted by boiling the beads in $1.5 \times$ Laemmli buffer and subjected to Western blot.

\section{Results}

Three nuclear export sequences of Olig1 regulate its export to the cytoplasm

Olig1 and Olig2 are highly conserved at the molecular and functional level, yet they have distinct subcellular localization during oligodendrocyte development (Arnett et al., 2004; Kitada and Rowitch, 2006; Niu et al., 2012). Therefore, we predicted that Olig1 must have nuclear export sequences (NES) not found in Olig2 and analyzed the Olig1 protein sequence for potential NES. Three consensus NES were identified either within or adjacent to the bHLH domain of Olig1 (Fig. 1A). The sequence of NES1 was fully conserved with Olig2, but there were two additional NES sequences in Olig1 (NES2 and NES3; Fig. 1 $A, B$ ). The three Olig1 NES were conserved across different species from mouse to human, but not zebrafish (Danio rerio; Fig. $1 B$ ).

To test the role of the conserved Olig1 NES in regulating nuclear export, GFP-tagged human Olig1 was transfected into primary cultured OPCs. In contrast to dominant nuclear location of Olig1 in OPCs in vivo, the majority of the Olig1-GFP (63.59\%) was evenly distributed in the nucleus and cytoplasm $(\mathrm{N}=\mathrm{C})$ in transfected OPCs in vitro (Fig. 1C,I). To test active export of Olig1-GFP after overexpression in cultured OPCs, cells were treated with the nuclear exportin inhibitor leptomycin. In contrast to untreated transfected cells (Fig. 1C), all of the Olig1-GFP 
A

A

162-ILLLGSSLEL-171

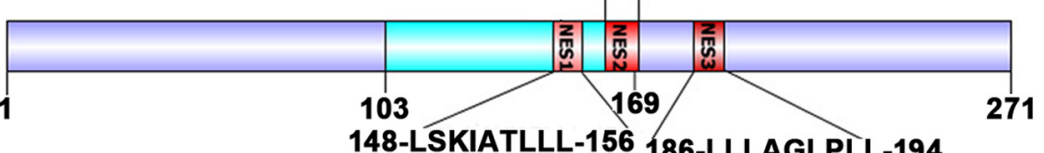

B

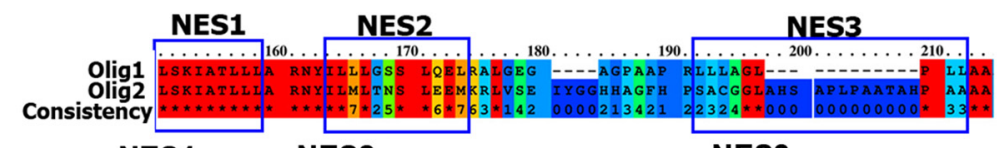

NES1

NES2

NES3

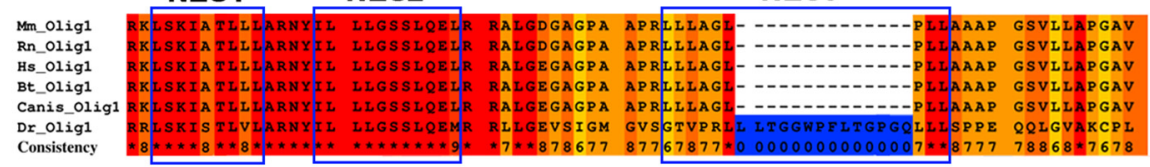

Unconserved 012345678910 Conserved
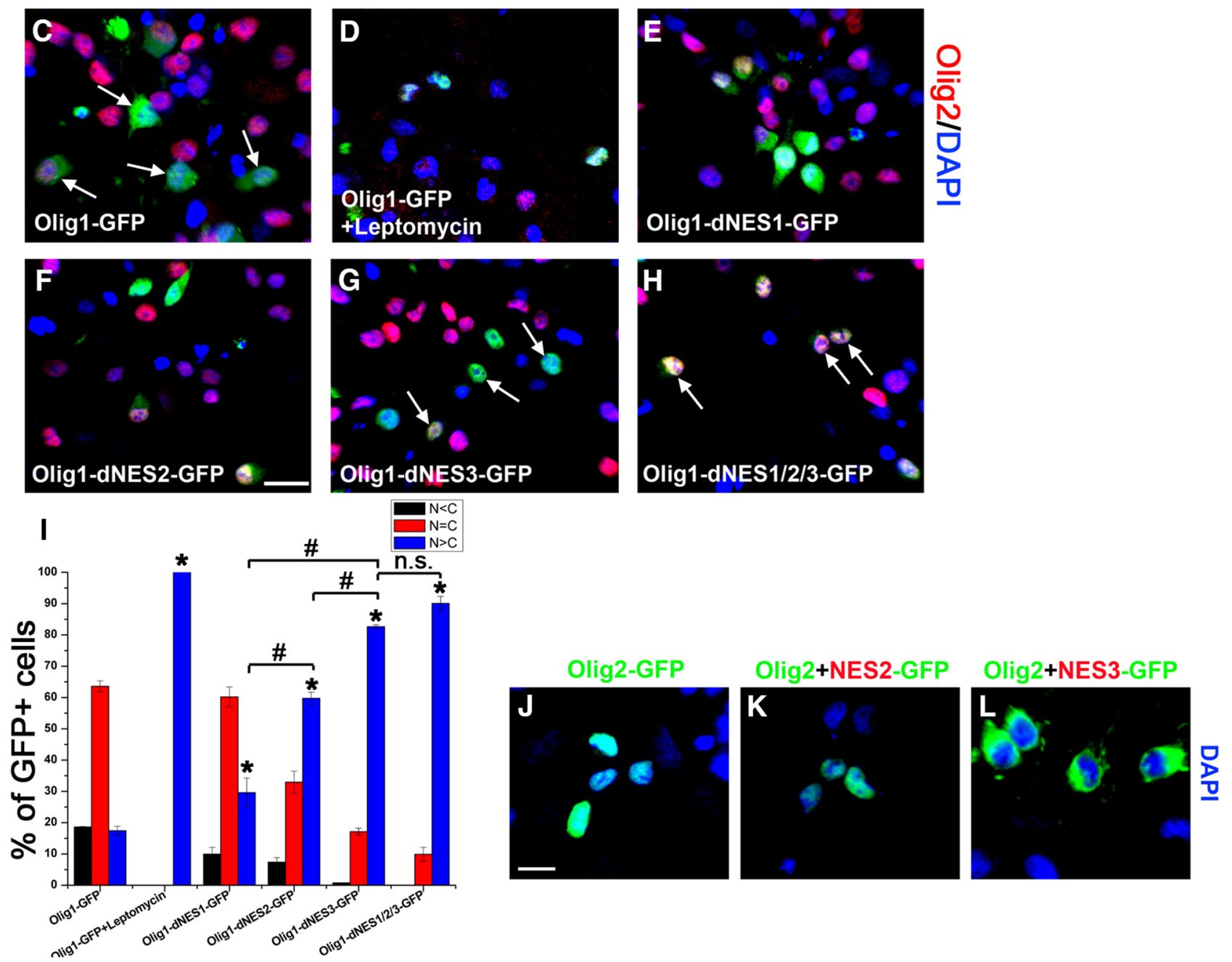

Figure 1. Three NESs of Olig1 regulate its export. A, Structural features of human Olig1 protein showing the conserved bHLH domain. Three predicted NESs, as determined by analysis with NetNES1.1, are highlighted in red. $\boldsymbol{B}$, Alignment of the bHLH domain of human 0lig1 and Olig2 (top). Note high conservation of NES1, with less for NES2 and NES3. Sequence of this 0lig1 region among different species with the three NES domains boxed in blue (bottom). Note unique $D$. rerio (zebrafish) sequence in blue highlight that dissupts NES3 in that species. $\boldsymbol{C}-\boldsymbol{H}$, Subcellular location of GFP-tagged Olig1 or its mutants deleted for the indicated NES sequences (dNES) $48 \mathrm{~h}$ after transfection into cultured rat OPCS. C, Olig1-GFP, note cytoplasmic localization (arrow). D, 0lig1-GFP plus leptomycin (20 nM); $\boldsymbol{E}$, Olig1-dNES1-GFP. $\boldsymbol{F}$, Olig1-dNES2-GFP. G, 0lig1-dNES3-GFP, note nuclear localization (arrow). $\boldsymbol{H}$, 0lig1-dNES1/2/3-GFP, note nuclear localization (arrow). Costained with Olig2 (red), DAPI (blue). Scale bar, $15 \mu \mathrm{m}$. Arrow labels transfected OPCs. I, Quantitative analysis of the subcellular distribution of Olig1-GFP or mutants imaged in $\mathbf{C}-\boldsymbol{H}$. Data were quantified as $\mathrm{N}<$ $C$ (black), $\mathrm{N}=\mathrm{C}($ red), or N $>C$ (blue). Data represent the mean \pm SEM from at least three independent experiments and, for each different construct in each experiment, at least 300 transfected cells were counted. The percentage of nuclear localization of indicated mutants was compared with that of WT 0lig1 ${ }^{*} p<0.05$ ) and between different mutants (\#p < 0.05; one-way ANOVA). $J$, $\boldsymbol{K}$, Impact of ectopic Olig1 nuclear export sequences on Olig2 subcellular location. Olig2-GFP $(\boldsymbol{J})$, chimeric Olig2 with nuclear export sequence 2 derived from 0lig1 (0lig2 + NES2-GFP; $\boldsymbol{K}$ ), and chimeric Olig2 with nuclear export sequence 3 derived from Olig1 (0lig2+NES3-GFP; $L$ ), note cytoplasmic localization. Scale bar, $10 \mu \mathrm{m}$. 

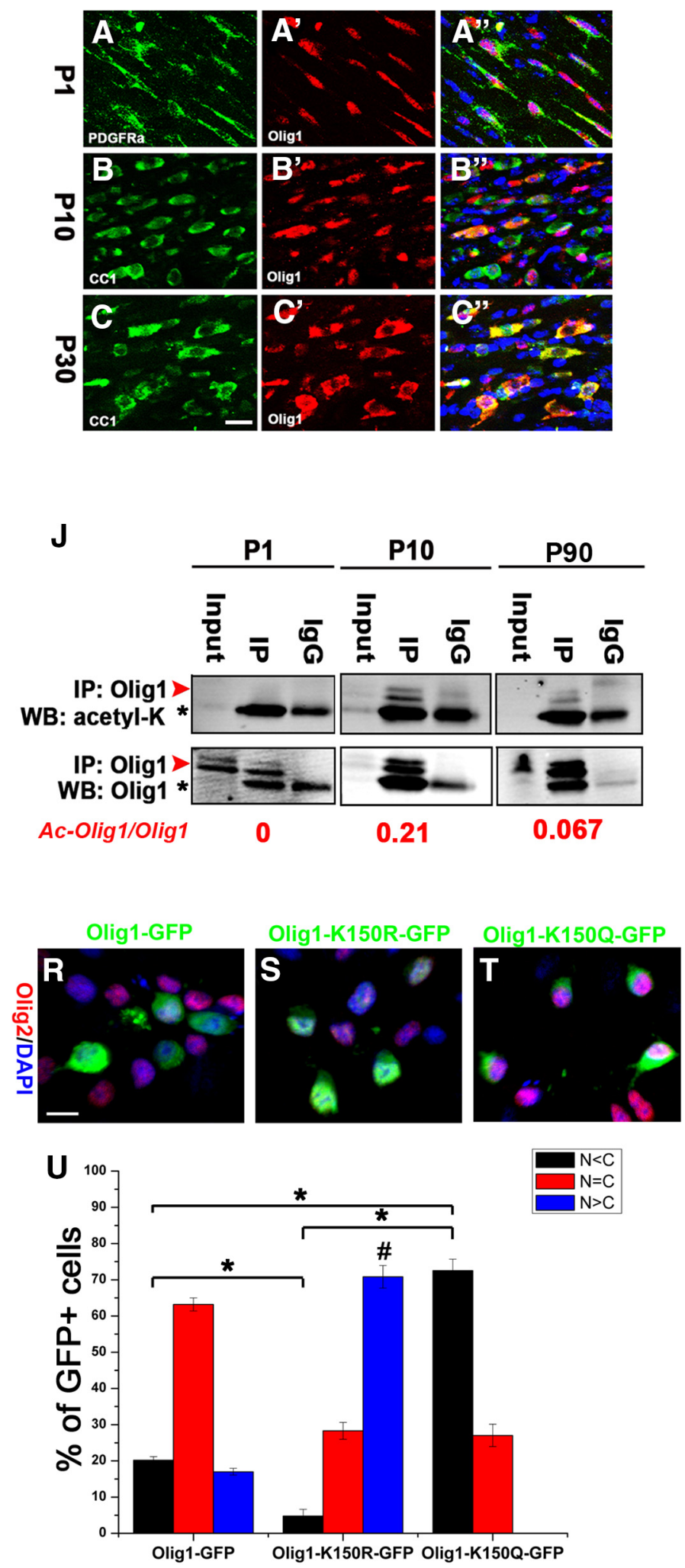

Figure 2. Acetylation of 0 lig1 is correlated with its cytoplasmic localization in developing mouse brain. $A-C$, Double immunostaining of 0lig1 (red, $\left.A^{\prime}, B^{\prime}, C^{\prime}\right)$ with PDGFR $\left(O P C S\right.$, green, $\left.A, A^{\prime \prime}\right)$ or CC1 (mature oligodendrocytes, green, $\left.\boldsymbol{B}, \boldsymbol{C}, \boldsymbol{B}^{\prime \prime}, \boldsymbol{C}^{\prime}\right)$ in corpus callosum of P1 $(\boldsymbol{A}), \mathrm{P} 10(\boldsymbol{B})$, or P30 (C) mice (blue in $\boldsymbol{A}^{\prime \prime}, \boldsymbol{B}^{\prime}, \boldsymbol{C}^{\prime}$ is DAPI). 0lig1 is in the nucleus of PDGFR $\alpha$-positive OPCs at P1 (A), switches from the nucleus to cytoplasm of C(1-positive oligodendrocytes at P10 (B), and is exclusively localized to the cytoplasm in C(1-positive cells at P30 (C). Scale bar, $20 \mu \mathrm{m}$. D-I, Primary

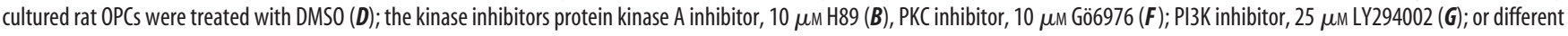

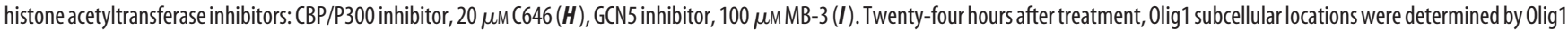
antibody staining (green) and costained with 0lig2 (red) or DAPI (blue). Scale bar, $15 \mu \mathrm{m}$. J, Olig1 was acetylated in developing mouse brain. Endogenous 0lig1 was immunoprecipitated from subcortical white matter homogenates of different postnatal ages as indicated and 0 lig1 acetylation was detected with general acetylated-lysine antibody. Arrowheads (red), 0 lig1; asterisks, rabbit IgG. Ratio of acetylated Olig1 to total Olig1 is indicated below in red. $\boldsymbol{K}$, Schematic illustrating the predicted acetylated lysine sites in the Olig1 bHLH domain and NES (Figure legend continues.) 
localization was nuclear after leptomycin treatment $(\mathrm{N}>\mathrm{C}$; Fig. $1 D, I)$. To investigate the role of the three Olig1 NES, they were deleted individually or collectively. After NES1, NES2, or NES3 were individually deleted, nuclear Olig1 increased significantly to 29.5\% (dNES1), 59.75\% (dNES2), and 82.64\% (dNES3), respectively, compared with $17.45 \%$ nuclear retention of wild-type Olig1 (Fig. $1 E, F, G, I$ ). Consistent with this, when all three Olig1 NES were collectively deleted, Olig1 cytoplasmic export was severely blocked, with $92.5 \%$ of Olig1 retained in the nucleus (Fig. $1 H, I)$. These data suggest that the three predicted NES regulate Olig1 export together and eliminating any one alters Olig1 export out of the nucleus to a different extent. Among them, NES3 functions as the strongest export signal. Interestingly, NES3 is the least conserved between Olig1 and Olig2 (Fig. 1B). To test whether the extra NES2 and/or NES3 of Olig1 could explain its nuclear export, in contrast to the predominant nuclear location of Olig2, we introduced NES2 or NES3 sequences into the Olig2 protein to examine directly their impact on Olig2 subcellular location. GFPtagged human Olig2 and chimeric Olig2 with NES2 or NES3 of Olig1 were transfected into primary cultured OPCs. Olig2-GFP was found predominantly in the nucleus, as is endogenous Olig2 (Fig. 1J). Surprisingly, adding the Olig1 NES2 sequence to Olig2 did not change its nuclear location (Fig. $1 K$ ), but inserting the NES3 sequence of Olig1 to Olig2 forced complete export of Olig2 to the cytoplasm (Fig. $1 L$ ). These data support the function of NES3 as a strong nuclear export signal because its insertion into Olig2 is sufficient to drive nuclear export of Olig2. However, despite the presence of the three NES sequences in Olig1, including the strong nuclear export signal NES3, the majority of Olig1 is not completely exported to cytoplasm in cultured OPCs. From this, we concluded that all three NES are necessary but not sufficient to drive the complete nuclear export of Olig1. Additional mechanisms must exist to regulate the active export of Olig1 from the nucleus.

\section{Acetylation of Olig1 is correlated with its cytoplasmic localization}

In the developing mouse brain, Olig1 localized only to the nucleus of OPCs that expressed PDGFR $\alpha$ at P1 (Fig. 2A). At P10, Olig1 was present in both the nucleus and the cytoplasm in maturing oligodendrocytes that expressed CC1 (Fig. 2B) and it was completely cytoplasmic in myelinating oligodendrocytes at 1 month (Fig. 2C). These results were consistent with previous findings (Arnett et al., 2004; Niu et al., 2012; Dai et al., 2015) and suggested that Olig1 translocation to the cytoplasm in maturing

\section{$\leftarrow$}

(Figure legend continued.) sequences, including K109, K116, K147, and K150. L-Q, Subcellular location of deacetylated mimic of four different predicted lysine sites in cultured rat OPCs. WT Olig1-GFP (L), Olig1-K109R-GFP (M), Olig1-K116R-GFP ( $\boldsymbol{N})$, Olig1-K147R-GFP (0), 0lig1K150R-GFP (P), or Olig1-K109K116K147K150R(4KR)-GFP (Q) mutants were transfected into the rat $0 \mathrm{PC}$ and 0 lig1 subcellular location was determined $48 \mathrm{~h}$ later and costained with 0 lig2 (red) or DAPI (blue). Scale bar, $15 \mu \mathrm{m}$. $\boldsymbol{R}-\boldsymbol{T}$, Acetylation of lysine (K), 150 on 0lig1 regulated its cytoplasmic localization in cultured rat OPCs. Olig1-GFP ( $\boldsymbol{R})$, 0lig1-K150R-GFP (S), or 0lig1K1500-GFP $(T)$ mutants were transfected into the rat OPCs and Olig1 subcellular location was analyzed $48 \mathrm{~h}$ later in transfected $0 \mathrm{Ls}$ using 0 lig2 (red) and DAPI (blue) to localize nuclei. Scale bar, $10 \mu \mathrm{m}$. U, Quantitative analysis of the subcellular distribution of Olig1-GFP or its mutants imaged in $\boldsymbol{R}-\boldsymbol{T}$. Data were quantified as nuclear $\mathrm{N}<\mathrm{C}$ (black), $\mathrm{N}=\mathrm{C}$ (red), or N $>$ C (blue). Data represent the mean \pm SEM from at least three independent experiments and, for each different construct in each experiment, at least 300 transfected cells were counted. The percentage of cytoplasmic localization of indicated mutants was compared with each other $\left({ }^{*} p<0.05\right)$ and nuclear localization of indicated mutants were compared with wild-type 0lig 1 (\#p<0.05; one-way ANOVA).
Table 1. Predicted Olig1 acetylation sites

\begin{tabular}{lcc}
\hline Peptide & Position & Score \\
\hline TAPLLPKAAREKP & 67 & 1.15 \\
PKAAREKPEAPAE & 72 & 1.91 \\
QQQLRRKINSRER & 109 & 0.81 \\
INSRERKRMQDLN & 116 & 1.07 \\
QGAPGRKLSKIAT & 147 & 2.10 \\
PGRKLSKIATLLL & 150 & 2.23 \\
DALRPAKYLSLAL & 218 & 1.80 \\
CTCAVCKFPHLVP & 251 & 1.51
\end{tabular}

Potential acetylation sites of human 0lig1 were predicted by the PAlL server (http://bdmpail.biocuckoo.org/ prediction.php) with a 0.75 threshold cutoff.

oligodendrocytes at P10 is an actively regulated process. The fact that, despite the presence of the three consensus nuclear export sequences in Olig1, its nuclear export occurs only in myelinating oligodendrocytes but not in OPCs suggests that additional modification of the Olig1 protein may regulate its translocation as oligodendrocytes mature.

Phosphorylation and acetylation are well known posttranslational modifications that can regulate the nuclear-cytoplasmic shuttle of many transcription factors (di Bari et al., 2006; Krämer et al., 2009). To test the role of phosphorylation or acetylation in regulating Olig1 nuclear to cytoplasmic translocation, we applied a variety of kinase inhibitors (protein kinase $A$, protein kinase $\mathrm{C}$ or Akt) and HAT inhibitors (C646, MB-3) to primary cultured OPCs (Fig. 2D-I). Only C646, which inhibits CBP and P300, blocked the nuclear to cytoplasmic translocation of Olig1 (Fig. $2 I$ ). This suggested that Olig1 acetylation could regulate its nuclear to cytoplasmic translocation.

To determine whether acetylation played a role in Olig1 translocation in vivo, we investigated whether Olig1 translocation from the nucleus to the cytoplasm correlated with increased Olig1 acetylation in the brain. At P1, when Olig1 was in OPC nuclei (Fig. 2A), it was very minimally acetylated (Fig. 2J, red arrowhead, not asterisk; note endogenous mouse Olig1 migrates very near normal IgG and is often the minor band seen above the nonspecific IgG band in blots of immunoprecipitated mouse tissue). The peak of Olig1 acetylation was at P10, when the Olig1 nuclear to cytoplasmic translocation occurred (Fig. 2B,J). At P30, Olig1 acetylation was reduced compared with P10 (Fig. 2J). Therefore, Olig1 acetylation increased during oligodendrocyte maturation in vivo, particularly during the translocation period, which suggested that Olig1 acetylation could regulate its cytoplasmic translocation, but it was not required for maintenance in the adult oligodendrocyte cytoplasm.

\section{Olig1 lysine (K) 150 acetylation regulated Olig1 cytoplasmic localization}

The Olig1 protein sequence was analyzed for potential acetylated lysines using the Prediction of Acetylation on Internal Lysines (PAIL) program ( $\mathrm{Li}$ et al., 2006), and four (K109, K116, K147, K150) potential acetylateable lysines were identified in the Olig1 bHLH domain (Fig. $2 K$, Table 1). Analysis of Olig1 protein sequences from different species revealed that the predicted lysine sites are conserved. Each lysine was mutated to arginine $(\mathrm{R})$ to generate individual mutants that mimic the deacetylated status and a mutant Olig1 with all four R mutations at K109, K116, K147, and K150 (4KR) was generated. These deacetylation-mimicking mutants were transfected into primary cultured OPCs and their subcellular location was determined (Fig. 2L-Q). K150 was the only lysine 

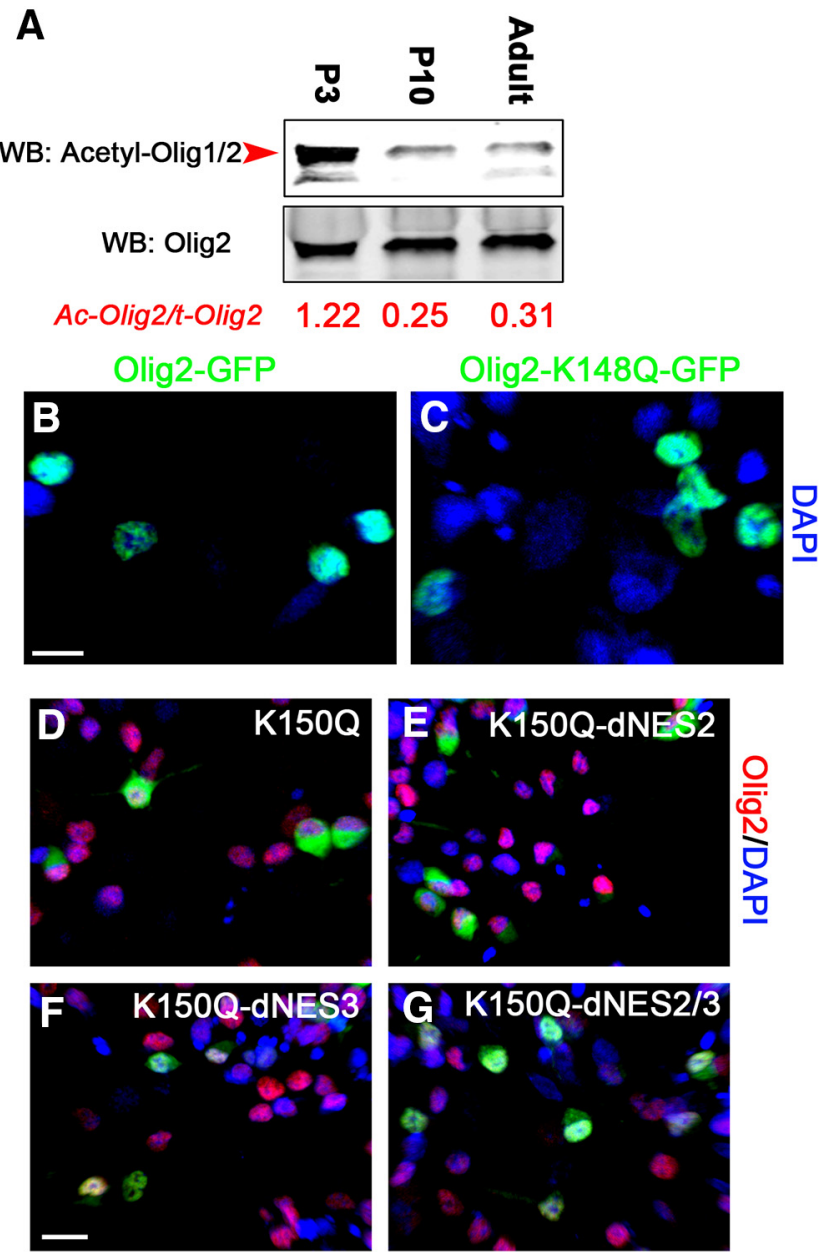

Figure 3. Acetylation of 0 lig2 does not alter its subcellular location. A, Olig2 was acetylated in developing mouse brain at P3. Endogenous Olig2 was immunoprecipitated from subcortical white matter homogenates of different postnatal ages as indicated and 0lig2 acetylation was detected with acetyl-0lig1-K150 antibody that targets the acetylated K150 epitope that is conserved between 0lig1 and 0lig2. Arrowheads (red), 0lig2. Ratio of acetylated Olig2:total 0 lig2 indicated below in red. Note it is high at P3. B, C, Acetylation of lysine (K) 148 on Olig2 (equivalent to K150 of Olig1) did not induce nuclear export of Olig2 in cultured rat OPCs. Olig2-GFP $(\boldsymbol{B})$ or 0lig2-K150Q-GFP $(\boldsymbol{C})$ mutants were transfected into the rat OPCs and Olig2 subcellular location was determined $48 \mathrm{~h}$ later using DAPI (blue) to localize nuclei. Scale bar, $10 \mu \mathrm{m}$. D-G, Acetylation of lysine (K) 150 on 0lig1 is insufficient to drive its nuclear export in cultured rat OPCs. Shown is the 0lig1 K150 acetylation mimic (0lig1-K150Q-GFP) or Olig1-K150Q mutant with deletion of the indicated NES sequences (dNES) $48 \mathrm{~h}$ after transfection into cultured rat OPCs. Olig1K150Q-GFP (D), 0lig1-K150Q-dNES2-GFP (E), 0lig1-K150Q-dNES3-GFP (D), and 0lig1K150Q-dNES2/3-GFP (D) using 0lig2 (red) and DAPI (blue) to localize nuclei. Scale bar, 15 $\mu \mathrm{m}$.

in the Olig1 NES (Fig. $2 K$ ) and K150R was the only single mutation that showed nuclear retention (Fig. $2 P$ ).

To further evaluate the role of K150 acetylation in regulating Olig1 subcellular localization, the K150 was mutated to glutamine (Q) to mimic acetylation or to arginine to mimic the nonacetylated form. WT-Olig1-GFP, Olig1-K150R-GFP, and Olig1-K150Q-GFP were electroporated into primary cultured rat OPCs. WT Olig1 was present in both the nucleus and cytoplasm (Fig. $2 R, U$ ), which was similar to endogenous Olig1 in cultured OPCs (see Fig. 9A). Nuclear retention of Olig1-K150R was found in $78.8 \%$ of the transfected OPCs (Fig. 2S,U). Strikingly, the acetylated Olig1 mimic Olig1K150Q was frequently found to be exclusively localized to rat OPC cytoplasm (Fig. 2T,U; 72.5\% C > N).
A
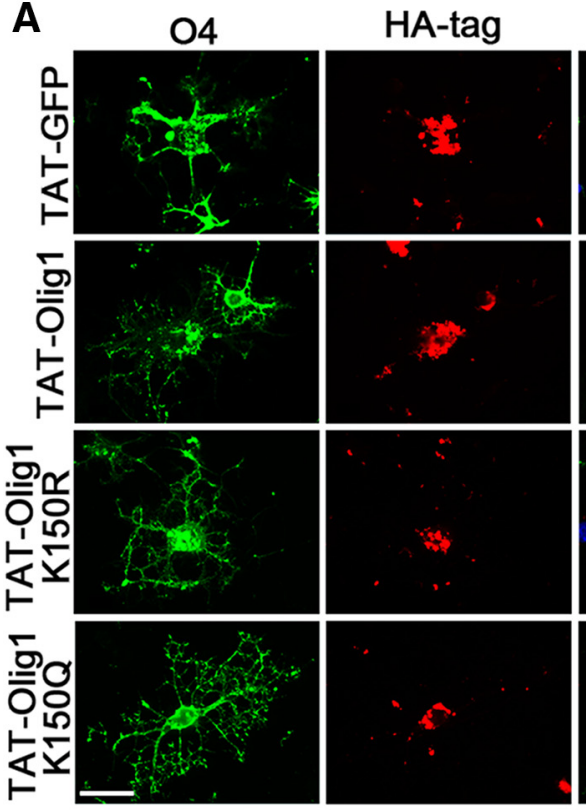

Merge
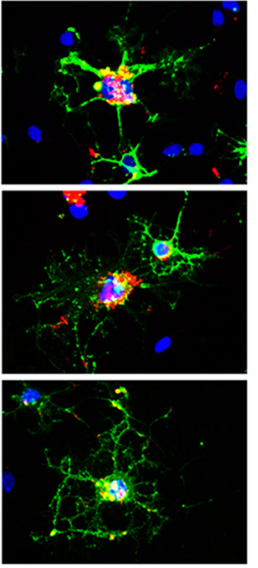

B

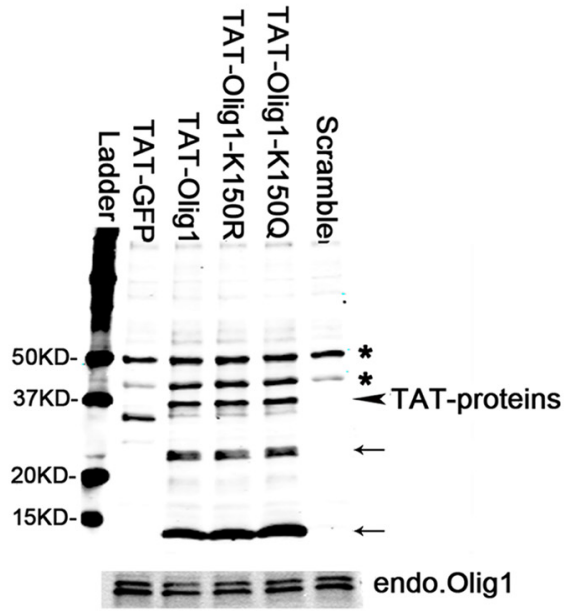

Figure 4. Transduction of primary oligodendrocyte with TAT-tagged purified Olig1 mutant proteins. $A$, Cultured rat oligodendrocytes were electroporated with smart pool control siRNA and recovered in proliferation media for $1 \mathrm{~d}$ and then shifted to differentiation medium with addition of either purified HA-tagged TAT-GFP, TAT-0lig1, TAT-0lig1-K150R, or TAT-0lig1$\mathrm{K} 1500$ protein $(0.4 \mu \mathrm{M})$. After differentiation for $1 \mathrm{~d}$, the cells were costained with 04 - and anti-HA-tagged antibodies. Scale bar, $50 \mu \mathrm{m}$. $\boldsymbol{B}$, Cultured rat oligodendrocytes were grown and treated as in $A$, collected, and immunoblotted with $\mathrm{HA}$ antibody and Olig1 antibody. Arrows, Olig1 degradation products; arrowhead, TAT-0lig1 protein; asterisks, nonspecific bands.

Interestingly, the lysine 150 site is located in the NES1 of Olig1 and this site is conserved in Olig2. To assess whether acetylation of K150 was unique to Olig1, the acetylation of Olig2 was studied in developing brain. An antibody was generated that specifically recognized acetylated K150 in Olig1 (see Fig. 6). That sequence is identical in Olig2 and, using that antibody on immunoprecipitation/Western blots of tissue samples, it was clear that Olig2 was acetylated at K148 (the equivalent lysine site in Olig2 for K150 in Olig1) in vivo (Fig. 3A). However, in contrast to Olig1, Olig2 K148 acetylation was found primarily at P1, likely in OPCs, and very little in myelinating oligodendrocytes at P10 or 3 months (Fig. 3A). This result indicates that, although Olig2 can be acetylated at the counterpart lysine site to that in Olig1, their acetylation is differently regulated. Clearly, acetylation of Olig2 is not sufficient to drive its nuclear export in OPCs in vivo. Further- 
TAT-GFP
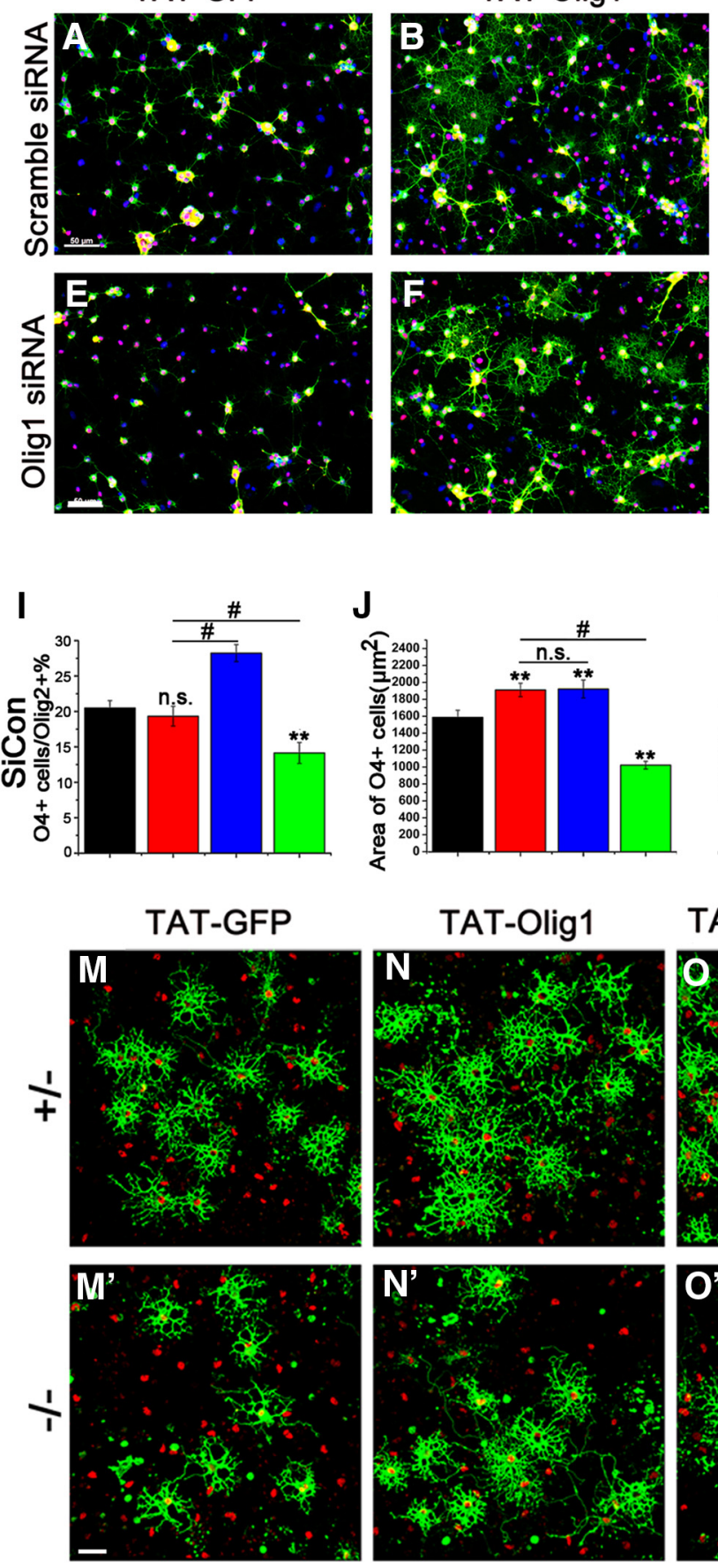

K
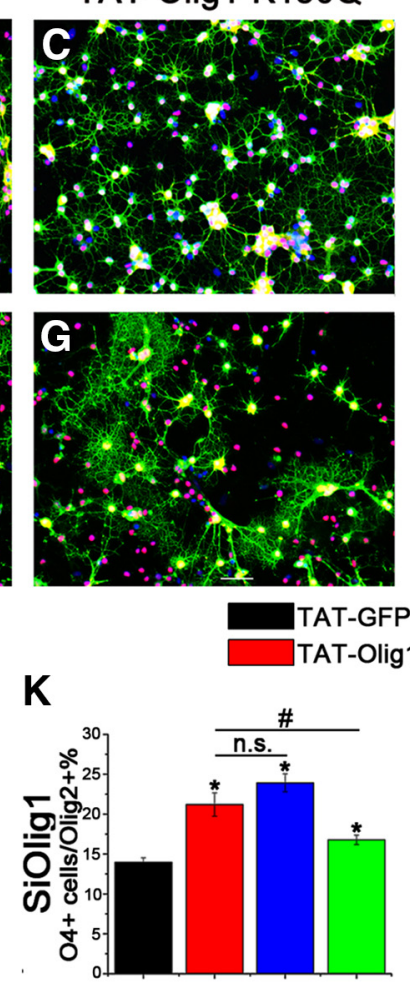

TAT-GFP

TAT-Olig1

$\mathbf{L}$

TAT-Olig1-K150Q

TAT-Olig1-K150R
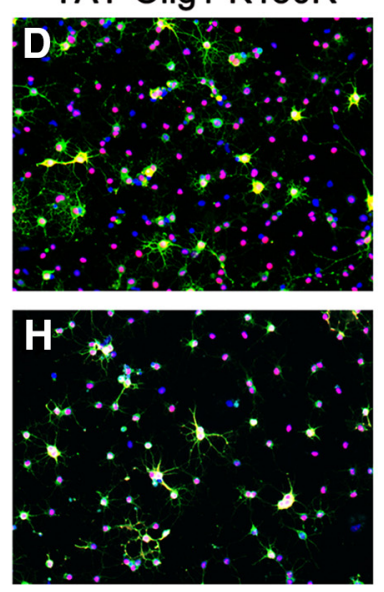

政
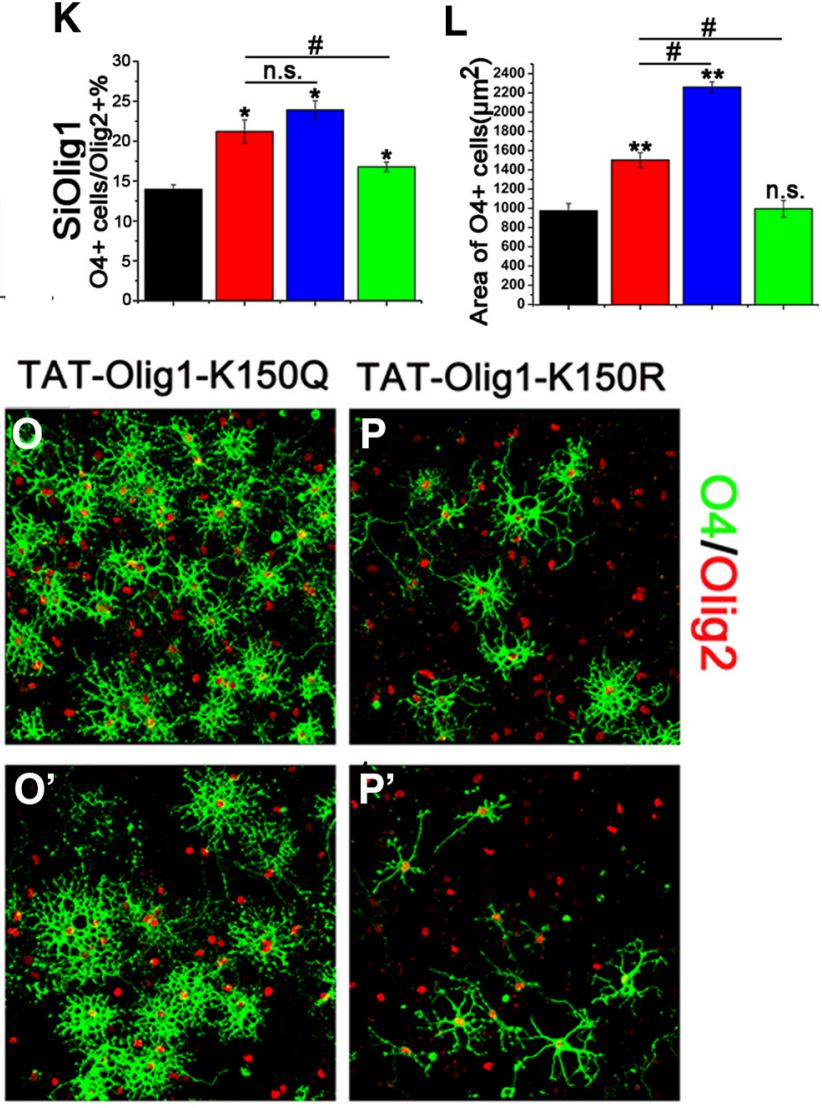

TAT-GFP TAT-Olig1-K150Q

TAT-Olig1 $\square$ TAT-Olig1-K150R
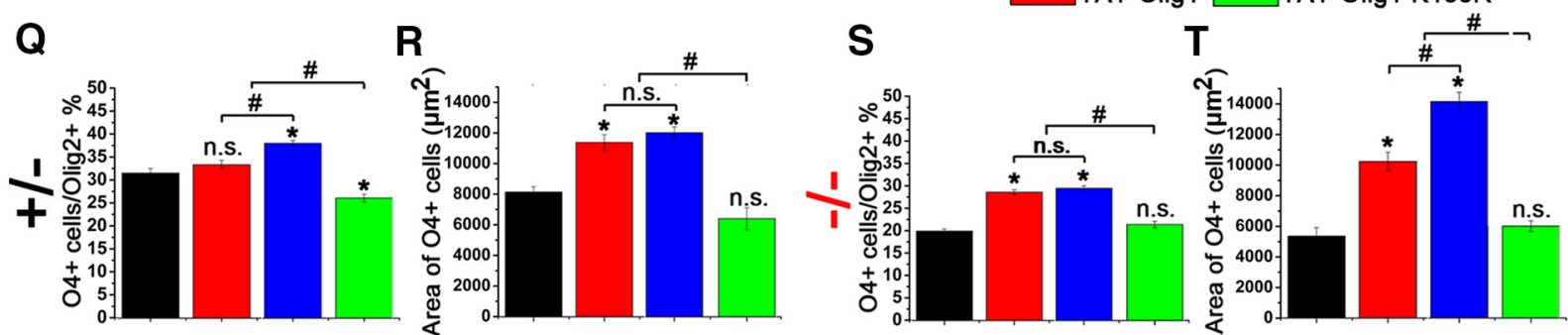

Figure 5. Acetylation of Olig1 is critical for its role in morphological differentiation and lineage progression. $\boldsymbol{A}-\boldsymbol{H}$, Cultured rat oligodendrocytes were electroporated with smart pool control siRNA $(\boldsymbol{A}-\boldsymbol{D})$ or 0 lig1 siRNA $(\boldsymbol{E}-\boldsymbol{H})$ and recovered in differentiation media for $1 \mathrm{~d}$. Cells were then switched to differentiation medium and purified TAT-GFP $(\boldsymbol{A}, \boldsymbol{E})$, TAT-0lig1 (B, $\boldsymbol{F})$, TAT-0lig1-K1500 $(\boldsymbol{C}, \boldsymbol{G})$, or TAT-0lig1-K150R $(\boldsymbol{D}, \boldsymbol{H})$ protein $(0.4 \mu \mathrm{M})$ was added. After differentiation for $1 \mathrm{~d}$, the cells were live stained with 04 antibody (green) and costained with 0 lig2 antibody (red). Scale bar, $50 \mu \mathrm{m}$. I-L, Quantitative analysis of the impact of TAT-GFP, TAT-0lig1, TAT-0lig1-K150R, or TAT-0lig1-K150Q protein transduction on OPC differentiation with control (Figure legend continues.) 
more, when an Olig2 lysine 148 acetylation mimic (Olig2K148Q) was transfected into primary culture OPCs, it was predominantly localized in the nucleus of OPCs (Fig. $3 B, C$ ). Importantly, acetylation of K150 in Olig1 was also not sufficient to drive Olig1 nuclear export in the absence of NES3 (Fig. 3D-G). Therefore, Olig1 acetylation at lysine 150 is required for its cytoplasmic localization in primary cultured oligodendrocytes, but the active nuclear export of Olig1 also requires the presence of NES3.

\section{Acetylation of Olig1 is critical for its role in morphological differentiation and lineage progression}

Our earlier studies (Dai et al., 2015) establish that Olig1 is critical for initial OPC differentiation both in culture and in mouse brain. Because Olig1 acetylation at K150 correlated with oligodendrocyte maturation both in vitro and in vivo, we examined whether Olig1 K150 acetylation had a direct impact on oligodendrocyte differentiation. To introduce the WT Olig1 or Olig1 lysine 150 mutants into differentiating OPCs, we treated cells with HA-tagged Olig1 protein linked to the cell-penetrating peptide TAT. TAT cell-penetrating peptide has been widely used to help transduce tagged protein into cells both in vitro and in vivo (Soane and Fiskum, 2005; Hotchkiss et al., 2006; Mi et al., 2012; O'Meara et al., 2013). The proteins were taken up by OPCs after $1 \mathrm{~d}$ of growth in differentiation medium plus purified TATtagged proteins, as demonstrated both by immunostaining and Western blotting (Fig. 4A,B). This allowed us to study overexpression of WT Olig1 or its lysine 150 mutants during oligodendrocyte differentiation. Control cells or Olig1-knock down cells were generated by electroporating OPCs with control siRNA (Fig. 5A-D) or Olig1 siRNA (Fig. 5E-H). Differentiation of control cells or Olig1-knock-down cells was then studied after incubation with TAT-tagged WT or mutant Olig1 proteins. Initial studies were done to analyze the effect of WT Olig1 overexpression in control cells that express endogenous Olig1. This overexpression did not influence their initial lineage progression, as measured by the number of O4-positive cells (Fig. 5A,B,I, cf. TAT-GFP-treated, TAT-Olig1-treated cells). However, WT Olig1 overexpression in control cells significantly increased their morphological differentiation, as measured by total covered area (Fig. $5 A, B, J$ ). The overexpression of the $\mathrm{K} 150$ acetylation mimic Olig1 K150Q in control cells significantly promoted both initial OPC differentiation to O4-positive cells (Fig. $5 A, C, I$ ) and their morphological differentiation (Fig. $5 A, C$, J). In contrast, overexpression of the K150 deacetylation mimic Olig1-K150R impaired OPC lineage progression and reduced the total covered area of

\section{$\longleftarrow$}

(Figure legend continued.) SiRNA shown in $\boldsymbol{A}-\boldsymbol{D}(\boldsymbol{I}, \boldsymbol{J})$ or after Olig1 siRNA knock-down shown in $\boldsymbol{E}-\boldsymbol{H}(\boldsymbol{K}, \boldsymbol{L})$. The percentage of 0lig2-positive cells that express $04(\boldsymbol{I}, \boldsymbol{K})$ and average covered area of 04 -positive cells $(\boldsymbol{J}, \boldsymbol{L})$ were quantified. $\boldsymbol{M}-\boldsymbol{P}$, Cultured mouse oligodendrocytes derived from 0lig1 heterozygous $(+/-; \boldsymbol{M}-\boldsymbol{P})$ or Olig1 null $\left(-/-; \boldsymbol{M}^{\prime}-\boldsymbol{P}^{\prime}\right)$ mice were differentiated for $3 \mathrm{~d}$ together with purified TAT-GFP $\left(\boldsymbol{M}, \boldsymbol{M}^{\prime}\right)$, TAT-0lig1 $\left(\boldsymbol{N}, \boldsymbol{N}^{\prime}\right)$, TAT-0lig1-K150Q $\left(\boldsymbol{O}, \mathbf{O}^{\prime}\right)$, or TAT-0lig1-K150R $\left(\boldsymbol{P}, \boldsymbol{P}^{\prime}\right)$ protein $(0.4 \mu \mathrm{M})$. Cells were live stained with 04 antibody (green) and costained with 0 lig2 antibody (red). Scale bar, $50 \mu \mathrm{m}$. Q- T, Quantitative analysis of the impact of TAT-GFP, TAT-0lig1, TAT-0lig1-K150R, or TAT-0lig1-K150Q protein transduction on differentiation of OPCs derived from either 0lig1 heterzygous neurospheres shown in $\boldsymbol{M}-\mathbf{P}(\mathbf{Q}, \boldsymbol{R})$ or Olig1-null neurospheres shown in $\boldsymbol{M}^{\prime}-\boldsymbol{P}^{\prime}(\boldsymbol{S}, \boldsymbol{T})$. The percentage of 0lig2-positive cells that express $04(\boldsymbol{Q}, \mathbf{S})$ and average covered area of 04-positive cells $(\boldsymbol{R}, \boldsymbol{T})$ were quantified. For all experiments, the data represent the mean \pm SEM from three independent experiments and, in each condition, at least 300 cells were examined visually and counted. Data of TAT-0lig1 or mutants treated group were compared with that of TAT-GFP treated group $\left({ }^{*} p<0.05\right.$, ${ }^{* *} p<$ 0.005 ) and between different mutants (\#p $<0.05$; one-way ANOVA).
O4-positive cells by $36 \%$, despite the presence of endogenous Olig1 (Fig. $5 A, D, I, J$ ). These results suggested that Olig1 acetylation at K150 is critical for promoting oligodendrocyte lineage progression and for morphological differentiation.

The role of Olig1 K150 acetylation in regulating oligodendrocyte differentiation was further examined in Olig1-knock down cells. As noted above, oligodendrocyte differentiation was significantly reduced upon Olig1 knock-down (cf. Fig. $5 A, E, I, K)$. Lineage progression (the percentage of $\mathrm{O} 4$-positive cells) and morphological differentiation were rescued by reintroduction of either WT Olig1 (Fig. $5 F, K, L$ ) or the acetylation mimic Olig1K150Q (Fig. 5G, K,L) and the impact of Olig1-K150Q on morphological differentiation was more dramatic than that of WT Olig1 (Fig. 5L). In contrast, the deacetylation mimic Olig1K150R failed to rescue the morphological differentiation defect after Olig1 knock-down (Fig. $6 H, L$ ). Consistent with these results (Fig. 5M-T), the TAT-Olig1 and the TAT-Olig1-K150Q acetylation mimic were also able to rescue the differentiation deficit of OPCs derived from Olig1-null mice (Fig. $5 N^{\prime}, O^{\prime}, S, T$ ), but the deactylated mimic TAT-Olig1-K150R was not (Fig. $\left.5 P^{\prime}, S, T\right)$. These results confirmed that $\mathrm{K} 150$ acetylation of Olig1 is critical for its role in oligodendrocyte differentiation and membrane expansion.

\section{Olig1 is acetylated at lysine 150 in vivo}

As noted above, to investigate the role of Olig1 K150 acetylation in vivo, antibodies specific to the acetylated lysine 150 of Olig1 were generated. We first started to identify the histone acetyltransferase (HAT) responsible for Olig1 acetylation at K150. Among the four major HATs, CBP (cAMP response elementbinding protein [CREB]-binding protein) and P300 (E1Abinding protein, $300 \mathrm{kDa}$ ) appeared most likely to be the HATs responsible for Olig1 acetylation at K150, since Olig1 nuclear export was blocked by CBP/P300 inhibitor C646 (Fig. 2I). Indeed, both CBP and p300 overexpression increased Olig1 acetylation in 293T cells (Fig. 6A,B). Furthermore, Olig1 K150 acetylation by CBP overexpression, but not P300, was largely abolished by the single mutation at lysine 150 in Olig1 (Fig. $6 A, B)$. These results confirm that $\mathrm{CBP}$ is the HAT responsible for Olig1 K150 acetylation.

Furthermore, the acetyl-Olig1-K150 (acetyl-Olig1) antibody specificity was confirmed by its ability to recognize purified WT Olig1 that was acetylated by CBP in vitro, but not the Olig1K150R mutant that could not be acetylated at K150 (Fig. 6C). Overexpression of CBP in HEK293T cells increased WT Olig1 acetylation at K150, but not that of the K150 de-acetylated mimic Olig1-K150R (Fig. 6D). Therefore, Olig1 was acetylated by CBP at $\mathrm{K} 150$ both in vitro and in vivo and this acetylated K150 could be specifically recognized by the acetyl-Olig 1 antibody.

To identify Olig1 K150 acetylation in developing mouse brain, endogenous Olig1 was immunoprecipitated from P3, P10, or 3 month subcortical white matter lysates or subcellular fractions. Consistent with our earlier results (Fig. $2 J$ ), studies with acetylOlig1 antibody demonstrated that Olig1 K150 acetylation peaked in the P10 fraction, when Olig1 translocation was occurring (Fig. $6 E$, red arrow). Furthermore, acetylated Olig1 K150 was enriched in the cytoplasmic fraction of the tissue, not the nuclear fraction. Acetylated Olig1 K150 was almost undetectable at P3 or adult in the cytoplasmic fraction, when Olig1 was either predominantly nuclear (P3) or cytoplasmic (adult), respectively. Weak Olig1 K150 acetylation was detected in the P10 nuclear fraction at the time Olig1 would be translocating to the cytoplasm but, interestingly, at 3 months, there was increased nuclear Olig1 K150 acet- 
ylation compared with P10 (Fig. 6E). Because Olig1 is not nuclear in mature oligodendrocytes in the adult, the acetylated nuclear Olig1 protein detected by Western blot is likely in adult OPCs. Overall, these studies suggest that acetylation of Olig1 at K150 is developmentally regulated and peaks when Olig1 is actively translocating from the nucleus to the cytoplasm.

Olig1 acetylation is regulated by preferentially interacting with $\mathrm{CBP}$ and HDAC1

Olig1 acetylation increased as OPCs differentiated to oligodendrocytes in vitro (Fig. 7A) and the interaction between Olig1 and CBP increased in the nucleus of differentiated cells compared with that in OPCs (Fig. 7B). Presumably, Olig1 acetylation must be regulated both by acetyltransferases and by deacetylases. To identify the Olig1 deacetylase, we coexpressed Olig1 with HDAC1 through HDAC10, Sirt1, or Sirt2 and immunoprecipitated samples to assess potential interactions. Olig1 interacted with HDAC1, HDAC2, HDAC3, HDAC4, HDAC10, and Sirt2 (data not shown). When Olig1 was coexpressed with these candidate HDACs plus excess CBP, HDAC1, HDAC3, and HDAC10 decreased Olig1 acetylation (Fig. 7C), but HDAC2, HDAC4, and Sirt2 did not (data not shown). HDAC1, HDAC3, and HDAC10 deacetylated Olig1 K150, the validated CBP acetylation site (Fig. 7C). Because HDAC1, HDAC3, and HDAC10 are also highly expressed in oligodendrocytes in the corpus callosum in vivo (Shen et al., 2005), these results suggested that HDAC1, HDAC3, and/or HDAC10 are present in oligodendrocytes and could potentially deacetylate Olig1 specifically at lysine 150 in vivo.

Interestingly, in vivo the Olig1 interaction was higher with HDAC1 in P3 brain (Fig. 7D) when deacetylated Olig1 was greater than acetylated Olig1 (Fig. 7D). Conversely, the increased interaction of Olig1 and CBP in P10 brain correlated with elevated Olig1 acetylation (Fig. 7E). Collectively, these data suggest that interaction between Olig1 and CBP or HDAC1 is developmentally regulated and this interaction could be responsible for the increased Olig1 acetylation as oligodendrocytes mature in vivo.

Olig1 is phosphorylated at serine 149 in vitro independent of its acetylation

Phosphorylaton of Olig 1 at serine 149 has been shown to regulate the nuclear export of Olig1 in primary cultured OPCs (Niu et al., 2012). Because the lysine 150 site that we identified is adjacent to this potential phosphorylation site, it is possible that phosphor-
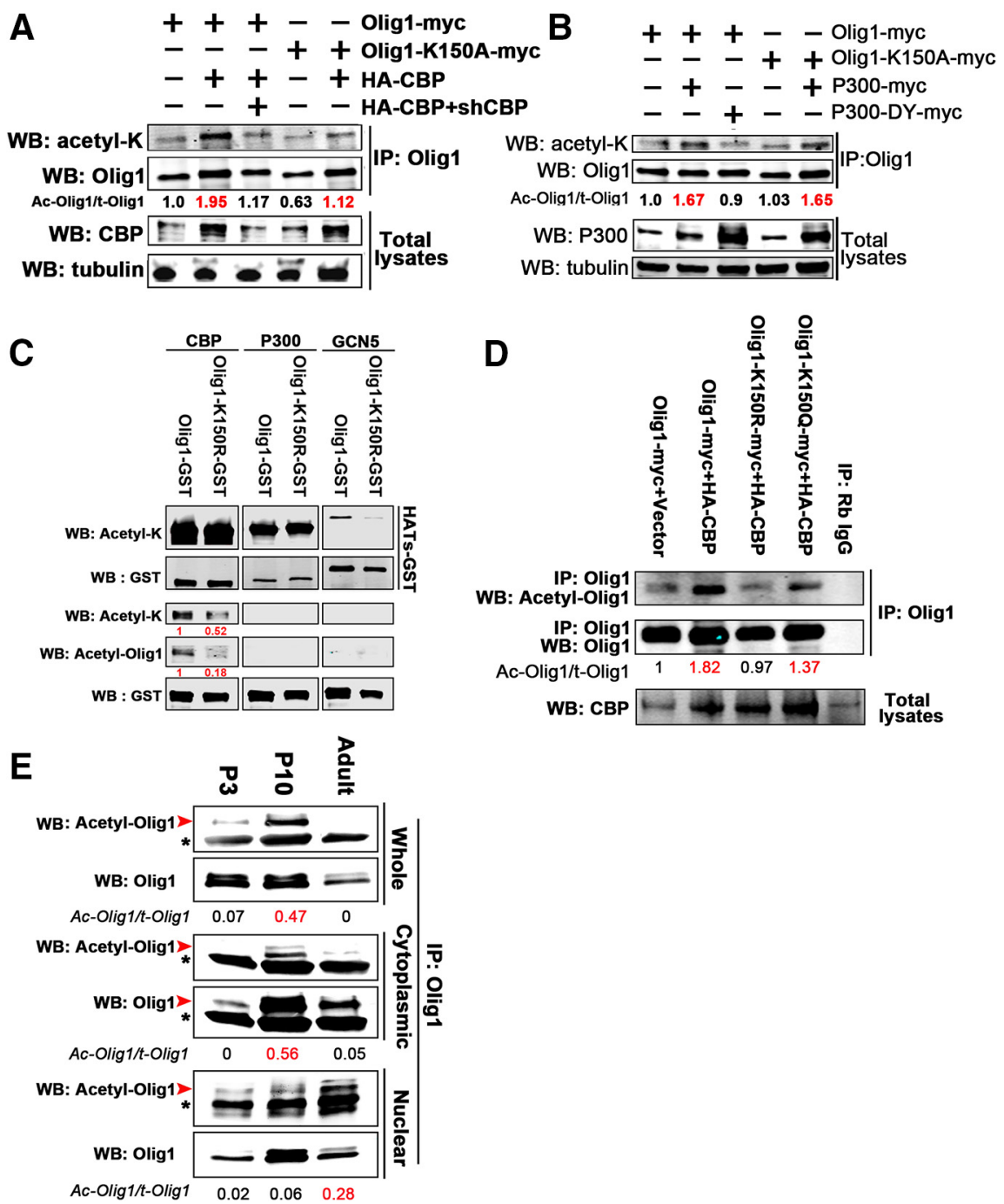

Figure 6. Olig1 is acetylated at lysine 150 in vivo. $\boldsymbol{A}, \boldsymbol{B}$, 0 lig1 is acetylated at lysine 150 by CBP in HEK293T cells. Olig1-myc or Olig1-K150A-myc was cotransfected with HA-CBP plus/minus CBP shRNA A, or with p300-myc or p300DY-myc (acetylase-deficient p300; $\boldsymbol{B})$ into HEK293T cells. Note increased acetylation in the presence of HA-CBP, which is reduced for 0lig1-K150A-myc $(\boldsymbol{A})$ or by the presence of shCBP. However, increased acetylation by P300 is comparable for WT 0lig1 and 0lig1 K150A-myc (B). C, The acetyl-0lig1-K150 antibody specifically recognized recombinant human 0lig1 protein acetylated on lysine 150 . One microgram of recombinant WT Olig1 or acetylation-deficient Olig1 mutant protein (0lig1-K150R) was incubated in vitro with purified CBP, P300, or GCN5 and their acetylation was detected by immunoblotting with acetyl-0lig1-K150 antibody, acetylated lysine antibody, or GST antibody. The activity of the different HATs was indicated by auto-acetylation of the GST-acetyltransferase detected by acetylated lysine antibody (top rows). The GST-0lig1 proteins were detected by GST immunostaining (bottom rows) and quantification of the ratio of acetylated Olig1 to total 0lig1 is presented in red, normalized to the WT control. D, Olig1 was acetylated at lysine 150 by CBP in HEK293T cells, as detected by acetyl-0lig1-K150 antibody. Olig1-myc, 0lig1-K150R-myc, or 0lig1-K1500-myc was cotransfected with HA-CBP into HEK293T cells. Twenty-four hours later, cells were treated with $500 \mathrm{~nm}$ TSA for $10 \mathrm{~h}$ to inhibit deacetylation before the cell lysate was immunoprecipitated with 0lig1 antibody and detected with acetyl-0lig1-K150 antibody. E, Olig1 was acetylated at lysine 150 in developing mouse brain. Subcortical white matter from P3, P10, or adult samples was fractionated and endogenous 0 lig1 was immunoprecipitated from whole lysates or cytoplasmic or nuclear fractions and immunoblotted with acetyl-Olig1-K150 antibody. Arrowheads (red), Olig1; asterisks (black), rabbit lgG. All data represent the results from three independent experiments. Quantification of the ratio of acetylated Olig1 to total Olig1 is indicated below in red.

ylation of serine 149 can disrupt the acetylation at lysine 150 . To test directly the impact of Ser149 phosphorylation on Olig1 nuclear export, S149 was mutated to aspartate (D) to mimic phosphorylation or to alanine to mimic the nonphosphorylated form. WT-Olig1-GFP, Olig1-S149A-GFP, and Olig1-S149DGFP were transfected into primary cultured rat OPCs (Fig. 8A$C)$. Surprisingly, in contrast to the dramatic influence of Olig1 acetylation on its nuclear export, neither the phosphorylated nor the nonphosphorylated Olig1 mimic showed different subcellu- 
A
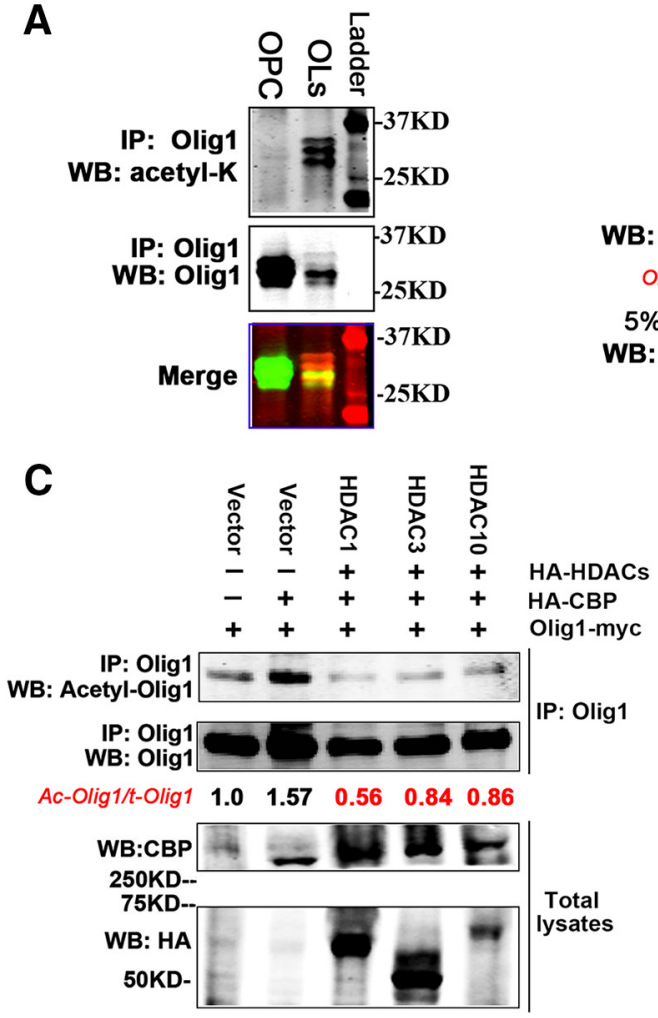

B

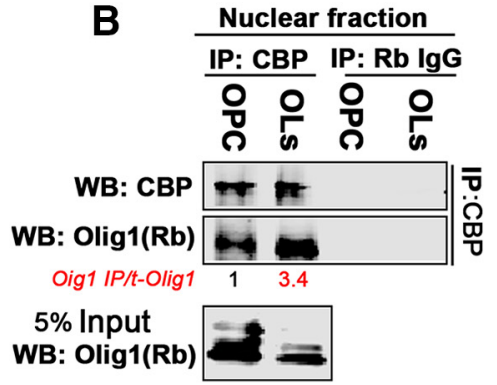

D

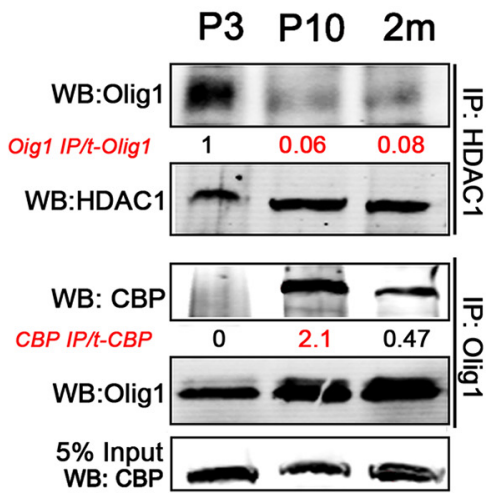

Figure 7. Olig1 acetylation is regulated by preferential interaction with CBP and HDAC1.A, 0lig1 was acetylated in cultured rat oligodendrocytes. Cultured rat $\mathrm{OPC}$ or oligodendrocyte cell lysates were immunoprecipitated with an 0 lig1 antibody and detected with an acetyl-lysine antibody (top) or Olig1 antibody (middle). Merged Western bands are shown in the bottom panel. $\boldsymbol{B}$, Olig1 interacted with CBP in nuclei of cultured rat oligodendrocytes and this interaction increased as oligodendrocytes differentiated. Nuclear lysates from rat OPCs or differentiated oligodendrocytes were immunoprecipitated with CBP antibody and detected with Olig1 antibody. Quantification of the ratio of immunoprecipitated 0lig1 to total 0lig1 indicated below in red, normalized to that from OPCS. C, HDAC1, HDAC3, and HDAC10 were potential HDACs responsible for 0lig1 acetyl-K150 deacetylation in vivo. The indicated constructs were cotransfected into HEK293T cells. Six hours after transfection, cells were treated with $500 \mathrm{~nm}$ TSA overnight and fresh medium was then added for another $10 \mathrm{~h}$. Cell homogenates were immunoprecipitated with 0lig1 antibody and detected with acetyl-0lig1-K150 antibody. Quantification of the ratio of acetylated 0lig1 to total 0lig1 is indicated below in red, normalized to that of empty vector. D, Olig1 preferentially interacted with HDAC1 or CBP in developing mouse brain. Endogenous HDAC1 was immunoprecipitated from subcortical white matter homogenates from different postnatal developmental ages and bound 0lig1 was detected with Olig1 antibody as indicated (top row). Endogenous Olig1 was immunoprecipitated from the same samples and bound (BP was detected with CBP antibody (middle row). Quantification of the ratio of immunoprecipitated Olig1 to total Olig1 (normalized to that from P3 tissue) and immunoprecipitated (BP to total (BP indicated below in red, normalized to that from OPCS. Note the high association of Olig1 and HDAC1 in P3 tissue and high association of Olig1 and CBP in P10 tissue.

lar distribution from wild-type Olig1 (Fig. $8 A-D$ ). These data suggest that serine 149 phosphorylation is not a major player in regulating Olig1 nuclear export in cultured oligodendrocytes. To examine directly the S149 phosphorylation of Olig1 in vivo, we raised an antibody against the phosphorylated S149 site of Olig1. Protein kinase A (PKA) was proposed to be the potential kinase responsible for Olig1 S149 phosphorylation (Niu et al., 2012). Indeed, overexpression of the PKA catalytic subunit (PKA-cat) in HEK293T cells increased WT Olig1 phosphorylation at S149, but not that of the S149 de-phosphorylated mimic Olig1-S149A (Fig. $8 E$ ). Therefore, Olig1 was phosphorylated by PKA at S149 in vitro and this phosphorylated S149 could be recognized specifically by the phospho-Olig1 antibody. Unfortunately, this antibody only detected the phosphorylation of endogenous Olig1 in primary cultured oligodendrocytes treated with PKA agonist forskolin, but not the basal level of Olig1 phosphorylation either in cultured oligodendrocytes or in developing mouse brain (Fig. $8 F, G$ ). After forskolin treatment, S149 phosphorylated Olig1 was predominantly found in the nuclear fraction of differentiated oligoden- drocytes (Fig. 8F, top). This nuclear enrichment of S149 phosphorylated Olig1 contrasted with the cytoplasmic enrichment of acetylated Olig1 as oligodendrocytes differentiated (Fig. $6 E$, middle). It indicated that Olig1 S149 phosphorylation and K150 acetylation may be independent. To examine directly the impact of K150 acetylation on Olig1 S149 phosphorylation, Olig1 K150 acetylation and deacetylation mimic mutants were transfected with PKA-Cat into HEK293T cells. Phosphorylation of both the Olig1 acetylation and deacetylation mimics, as detected by the phosphorylation-specific antibody, was decreased $>3$-fold compared with wild-type Olig1 (Fig. $8 H$ ). These data suggest that neither K150 acetylation nor deacetylation has a specific impact on Olig1 S149 phosphorylation because either loss or gain of K150 acetylation of Olig1 had the same impact. It is possible that the reduction of apparent phosphorylation of S149 after K150 mutation is caused by reduced phosphoOlig1 antibody affinity because of a conformational change caused by amino acid substitution at K150 site. Collectively, our results suggest that the S149 site of Olig1 can be phosphorylated independently of K150 acetylation. However, the basal level of Olig1 S149 phosphorylation in vivo is too low to be detected and this phosphorylation does not regulate Olig1 nuclear export.

\section{Increased acetylation of Olig1} decreased its chromatin binding and preceded its active nuclear export

For many transcription factors or chromatin-binding complexes, dissociation from chromatin precedes their inactivation or nuclear export (Niida et al., 2007; Nakamura et al., 2012). In the developing mouse brain, complete nuclear extrusion of Olig1 is seen in actively myelinating oligodendrocytes (Arnett et al., 2004; Dai et al., 2015). However, we saw only partial cytoplasmic translocation of Olig1 in fully differentiated oligodendrocytes in vitro (Fig. 9AC). We hypothesized that Olig1 nuclear export is a three successive step process: (1) Olig1 dissociation from chromatin, (2) reduced interaction of Olig1 with potential nuclear retention proteins, and (3) active export of Olig1 from the nucleus. To test whether the chromatin dissociation of Olig1 and its subsequent nuclear export was partially uncoupled in cultured oligodendrocytes, endogenous Olig1 was immunoprecipitated from the nuclear fraction of OPCs and mature oligodendrocytes and analyzed for its histone association. Histone $\mathrm{H} 3$ was strongly associated with Olig1 in OPCs, but not in mature oligodendrocytes, which had elevated Olig1 acetylation (Fig. 9E). Therefore, although some Olig1 was present in the nucleus in mature oligodendrocytes in vitro, most nuclear Olig1 in these differentiating cells was not bound to the chromatin. Olig1 chromatin association was examined directly by separating the chromatin-bound 

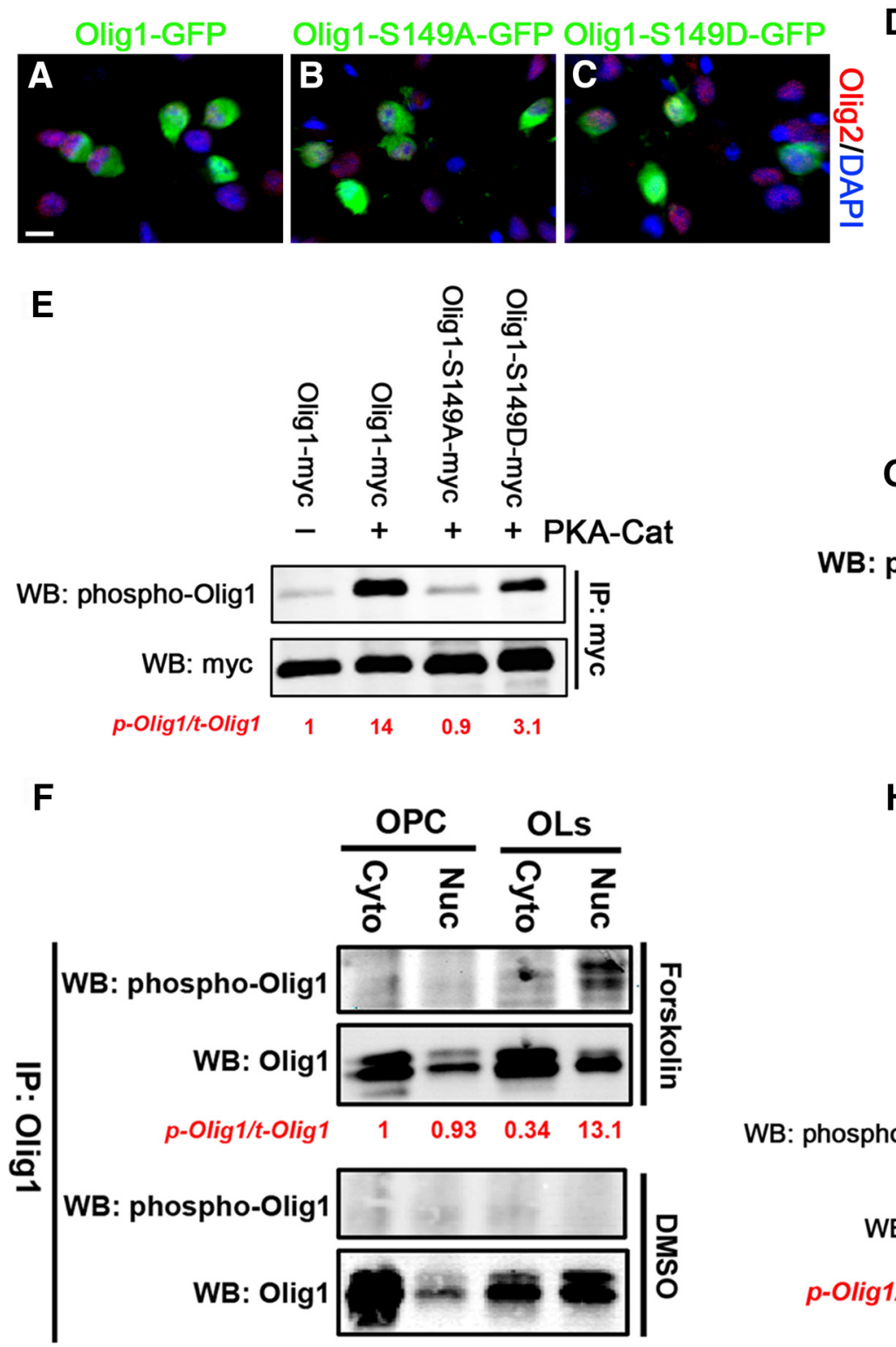

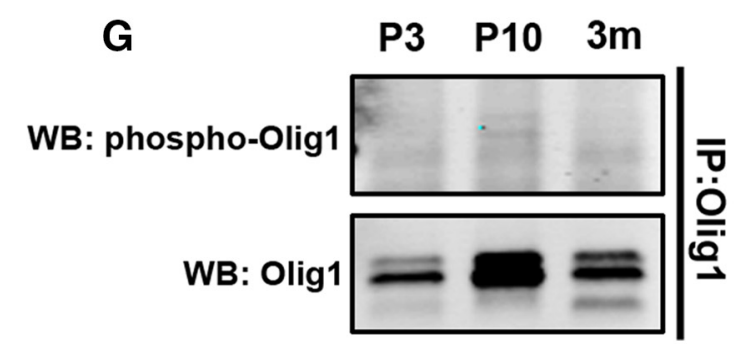

H

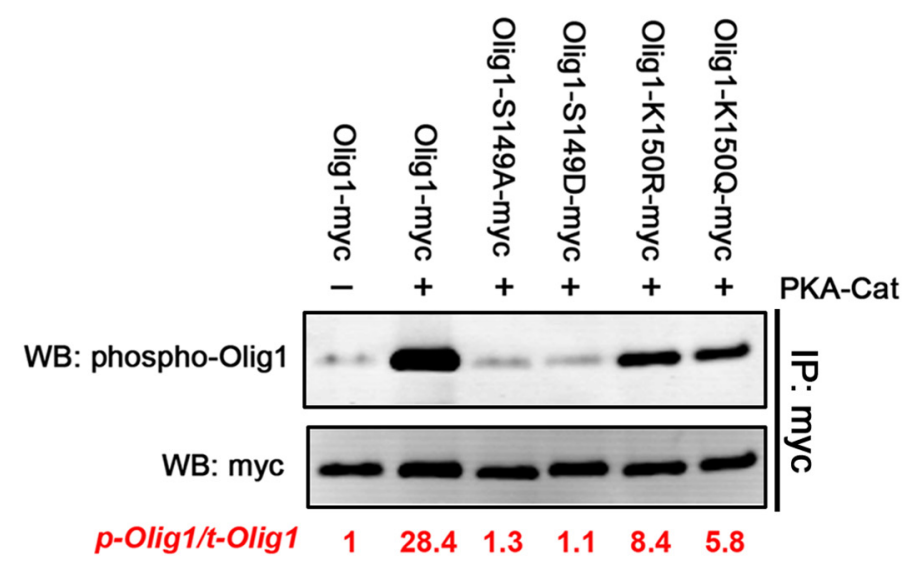

Figure 8. Olig1 is phosphorylated at serine 149 in vitro independent of its acetylation. $\boldsymbol{A}-\boldsymbol{C}$, Phosphorylation of serine (S) 149 on Olig1 did not alter its subcellular localization in cultured rat $0 \mathrm{PCS}$. Olig1-GFP ( $\boldsymbol{A})$, Olig1-S149A-GFP ( $\boldsymbol{B})$, or Olig1-S149D-GFP ( $\boldsymbol{C}$ ) mutants were transfected into the rat OPCs and Olig1 subcellular location was determined $48 \mathrm{~h}$ later in transfected 0Ls, using 0 lig2 (red) and DAPI (blue) to localize nuclei. Scale bar, $10 \mu \mathrm{m}$. D, Quantitative analysis of the subcellular distribution of 0lig1-GFP or its $\mathrm{S149}$ mutants shown in $\boldsymbol{A}-\boldsymbol{C}$. Data were quantified as $\mathrm{N}<\mathrm{C}$ (black), $\mathrm{N}=\mathrm{C}($ red), or $\mathrm{N}>\mathrm{C}$ (blue). Data represent the mean \pm SEM from at least three independent experiments and, for each different construct in each experiment, at least 300 tranfected cells were counted. The percentage of nuclear or cytoplasmic localization of indicated mutants was compared with each other. No significant different were found between different mutants (one-way ANOVA).E, Olig1 was phosphorylated at serine 149 by PKA in HEK293T cells detected by phospho-0lig1-S149 specific antibody. Olig1-myc, Olig1-S149A-myc, or 0lig1-S149D-myc was cotransfected with catalytic subunit of PKA (PKA-cat) into HEK293T cells. Twenty-four hours later, cells were collected and lysate was immunoprecipitated with myc tag antibody and detected with phosphoOlig1-S149 antibody. $F$, Olig1 was phosphorylated at serine 149 in rat oligodendrocytes only after forskolin treatment. Primary cultured OPCs or differentiated oligodendrocytes were treated with DMS0 or forskolin $(20 \mu \mathrm{m})$ for $16 \mathrm{~h}$, fractionated and the subcellular fractions were immunoprecipitated with Olig1 antibody and detected with phospho-0lig1-S149 antibody. G, 0lig1 phosphoryaltion at serine 149 site was not detected in developing mouse brain. Endogenous 0 lig1 was immunoprecipitated from subcortical white matter homogenates of different postnatal ages and 0 lig 1 phosphorylation was detected with phospho-0lig1-S149 antibody. $\boldsymbol{H}$, Acetylation at K150 had little specific impact on phosphorylation of serine 149 site of 0lig1. Olig1-myc, 0lig1-S149A-myc, Olig1-S149D-myc, Olig1-K50R-myc, or Olig1-K1500-myc was cotransfected with catalytic subunit of PKA (PKA-cat) into HEK293T cells. Twenty-four hours later, cells were collected and lysate was immunoprecipitated with myc tag antibody and detected with phospho-0lig1-S149 antibody. All data represent the results from three independent experiments. Quantification of the ratio of phosphorylated Olig1 to total Olig1 indicated below in red, normalized to control.

or chromatin-free proteins in the nuclear fraction. More Olig1 was found in the chromatin-free nuclear fraction in mature oligodendrocytes than in OPCs (Fig. 9D).

Interestingly, in adult samples in vivo, there was increased Olig1 acetylation at K150 in the nuclear fraction (Fig. 6E, bottom). Because nuclear Olig1 is exclusively found in OPCs, this suggests that, in adult OPCs, Olig1 may dissociate from chroma- tin, but the additional mechanism required for subsequent nuclear export is lacking, which is different from the coupled chromatin dissociation and nuclear export of Olig1 in OPCs at P10. To examine directly the impact of Olig1 acetylation on its association with chromatin in vivo, endogenous Olig1 was immunoprecipitated from the nuclear fraction of subcortical white matter obtained from P3, P10, or 3 month brains. More histone 
A

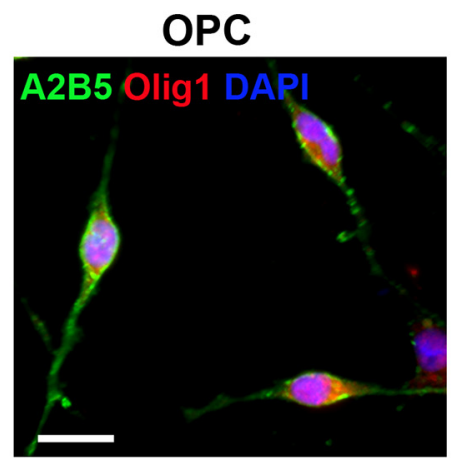

C

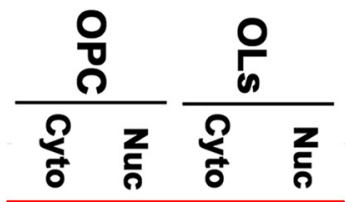

WB: Olig
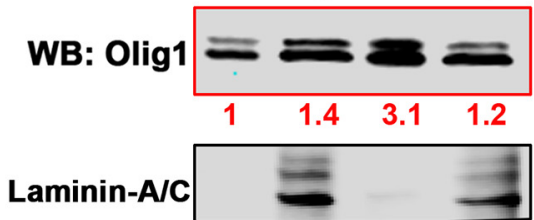

GAPDH
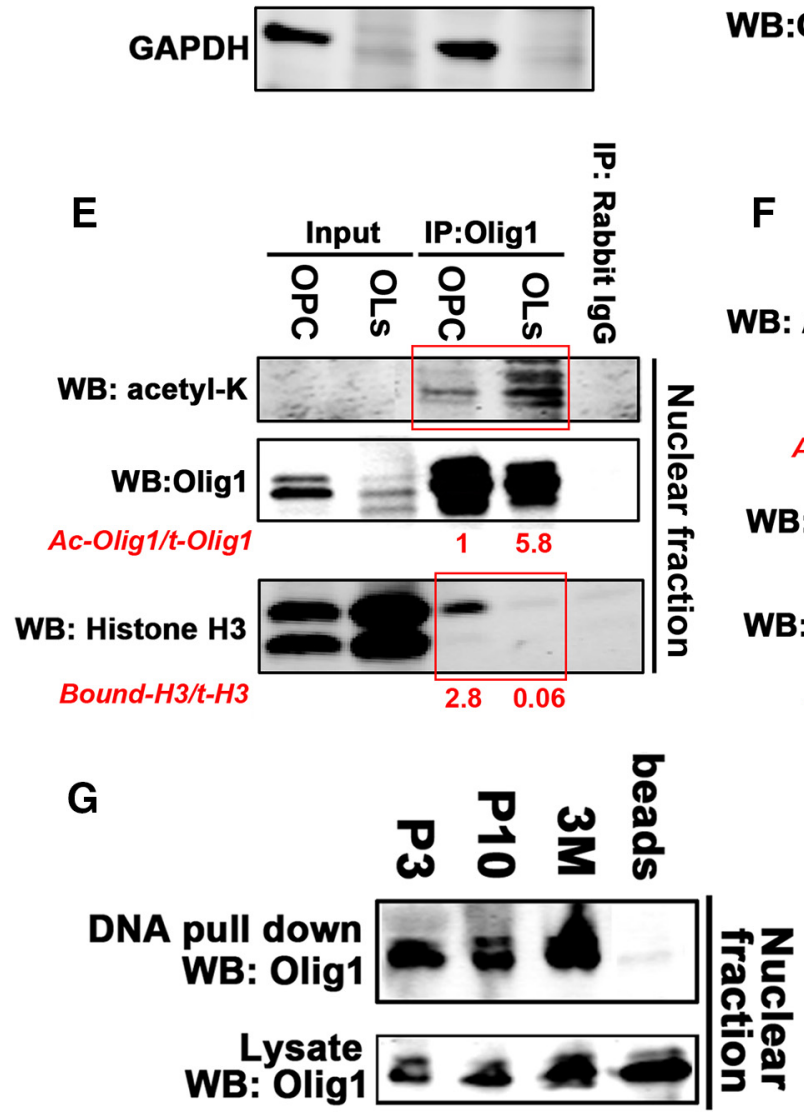

B Mature oligodendrocyte

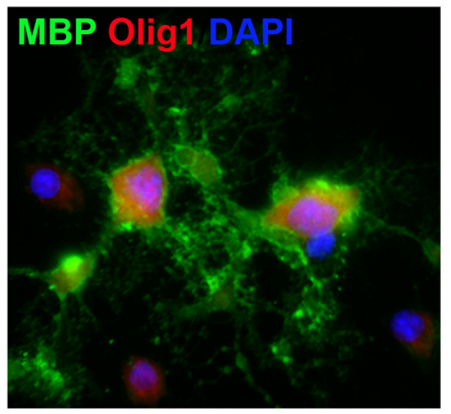

D Chromatin association

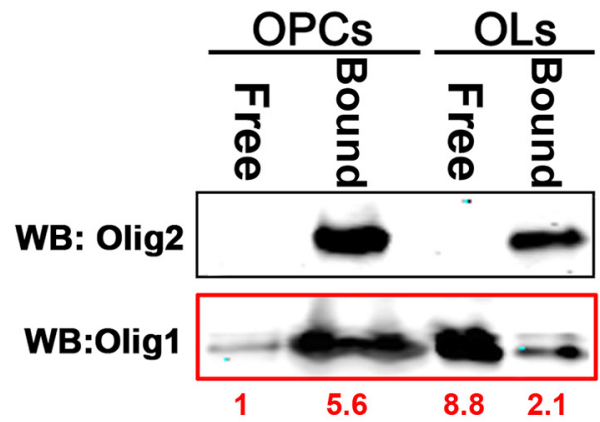

$\mathbf{F}$

WB: Acetyl-Olig1

WB: Olig1

Ac-Olig1/t-Olig1
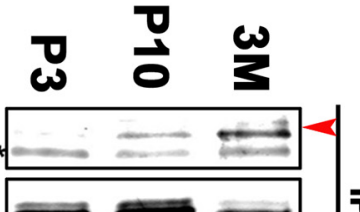

WB: Histone H3

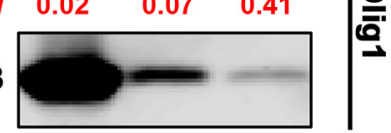

WB: Histone H3
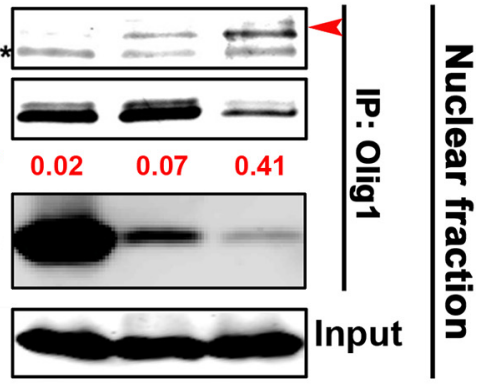

Bound-H3/t-H3 $\quad 1.57 \quad 0.25 \quad 0.09$

Figure 9. Increased acetylation of 0lig1 decreased its chromatin binding as oligodendrocytes differentiated. $A, B$, Primary cultured rat OPCs were either maintained in proliferation media for $3 \mathrm{~d}$ (A) or differentiated for another $5 \mathrm{~d}$ and stained with Olig1 antibody (red). OPCs were detected with A2B5 (green) and mature oligodendrocytes were labeled with MBP. Scale bar, $15 \mu \mathrm{m}$. C, Some Olig1 was retained in the nucleus of mature oligodendrocytes in culture. Nuclear and cytoplasmic fractions were isolated from cultured OPCs or differentiated oligodendrocytes. The subcellular distribution of endogenous Olig1 was determined by Western blot. Laminin A/C and GAPDH were used as markers for nuclear and cytoplasmic fractions, respectively (bottom row). Quantification of the 0 lig1 level is indicated in red and normalized to that of the cytoplasmic OPC fraction. D, Olig1 dissociated from chromatin as oligodendrocytes differentiated in vitro. The chromatin and soluble nuclear fractions of cultured OPCS (PDGF/bFGF, $3 \mathrm{~d}$ ) or differentiated oligodendrocytes (T3,3 $\mathrm{d}$ ) were isolated by subnuclear fractionation and the presence of 0lig1 or 0lig2 in either the soluble or pelleted chromatin fraction was determined by Western blot. Note the presence of Olig1 primarily in the chromatin pellet in OPCs, but primarily in the soluble fraction, dissociated from chromatin, in cultured oligodendrocytes. Quantification of the Olig1 level indicated in red and normalized to that from chromatin-free fraction of OPCs. E, Binding of Olig1 with Histone (Figure legend continues.) 
$\mathrm{H} 3$ interacted with Olig1 in P3 brain nuclei than in P10 nuclei, and much less association was seen in 3 month brain nuclei (Fig. $9 F)$. Conversely, despite reduced binding to chromatin in adult brain, Olig1 from all ages tested had comparable binding to DNA itself (Fig. 9G). Therefore, changes in the direct DNA binding of Olig1 cannot account for the dissociation of Olig1 from chromatin in differentiating oligodendrocytes, suggesting that additional mechanisms must be involved. Collectively, these data suggest that, as oligodendrocytes mature, Olig1 acetylation facilitates its dissociation from chromatin, which precedes its subsequent nuclear export.

\section{Acetylation of Lysine 150 on Olig1 increased its binding affinity for Id 2}

We hypothesize that Olig1 acetylation reduces its binding with potential nuclear retention proteins and facilitates its nuclear export. Olig1 can dimerize with other bHLH transcription factors such as Olig2, Olig1, Id2, Id4, and E47 or the non-bHLH transcription factor Sox10 (Samanta and Kessler, 2004; Li et al., 2007). We therefore investigated whether Olig1 acetylation changes its binding affinity for these known binding partners. We analyzed the interactions of WT Olig1, Olig1-K150R, or Olig1K150Q with Olig1, Olig2, E12/E47, Id4, or Id2 upon overexpression in HEK293T cells. All proteins interacted with WT Olig1 or the acetylation mimic Olig1-K150Q and Olig1, Olig2, and E12/ E47 bound comparably to WT and the deacetylation mimic Olig1-K150R (data not shown). Sox10 had slightly increased binding to Olig1-K150R and reduced binding to Olig1-K150Q (Fig. 10A), suggesting that it binds preferentially to deacetylated Olig1. However, Olig1-K150R had reduced binding affinity for Id2 (Fig. 10B), but not Id4 (Fig. 10C), suggesting that Id2 might be a specific partner for acetylated Olig1.

Id2 is a negative regulator of oligodendrocyte differentiation and undergoes nuclear to cytoplasmic translocation upon oligodendrocyte differentiation in vitro (Wang et al., 2001). The subcellular localization of Id 2 in the developing mouse brain was predominantly in the nucleus of OPCs at P4 and it either translocated to the cytoplasm or was downregulated in mature oligodendrocytes at P15 (Fig. 10D). The nuclear to cytoplasmic translocation of Id 2 and Olig1 occurred over the same time period in vivo. To assess possible interactions of these proteins in vivo, we analyzed cytoplasmic and nuclear fractions from P3, P10 or 3 month mouse subcortical white matter for Id2 localization and interactions. Endogenous Id 2 was immunoprecipitated from the cytoplasmic or nuclear fractions and immunoblotted with

\footnotetext{
$\leftarrow$

(Figure legend continued.) $\quad \mathrm{H} 3$ decreased as Olig1 acetylation increased in cultured oligodendrocytes. Mouse OPCs were maintained in PDGF/bFGF for $3 \mathrm{~d}$ or differentiated for $5 \mathrm{~d}$. Cell lysates were then immunoprecipitated with Olig1 antibody and immunoblotted for acetyl-lysine or histone H3 association (note boxed area). Quantification of the ratio of acetylated Olig1 to total Olig1 and indicated in red, normalized to that from OPCS, and Olig1-bound histone $\mathrm{H} 3$ is indicated in red. $\boldsymbol{F}$, In developing mouse brain, Olig1 binding with histone $\mathrm{H} 3$ decreased as oligodendrocytes matured. Subcortical white matter from different postnatal ages was fractionated into nuclear and cytoplasmic fractions. Endogenous 0 lig1 was immunoprecipitated from the nuclear fraction with 0lig1 antibody. Olig1 acetylation was detected with acetyl-0lig1-K150 antibody (top), and Olig1-bound histone H3 was detected with histone $\mathrm{H} 3$ antibody. Arrowheads, Acetyl-0lig1; asterisks, rabbit lgG. Note increase in acetylated Olig1 with age at the same time that the 0lig1 association with histone decreased. Quantification of the ratio of acetylated 0 lig 1 to total 0 lig 1 and 0 lig 1 bound histone $\mathrm{H} 3$ to total histone $\mathrm{H} 3$ indicated in red. G, DNA-binding affinity of Olig1 did not change as oligodendrocytes matured in the developing mouse brain. The same nuclear fractions as in $\boldsymbol{E}$ were incubated with a streptavidincoupled tandem E-box consensus DNA probe. Endogenous Olig1 was pulled down with DNA probes and detected with Olig1 antibody. Note comparable association of Olig1 with DNA regardless of the age of the samples. All data represent the results from three independent experiments.
}

Olig1 antibody. Olig1 was found to interact strongly with Id 2 in the cytoplasmic fraction at P10, but not at 3 months (Fig. 10E). The Olig1/Id2 interaction was not found in the nuclear fraction (Fig. 10E, bottom). The strong Olig1/Id2 interaction in the P10 mouse cerebrum cytoplasm correlated with high acetylation of Olig1 at K150 (Fig. 10E). Because Id2 is also expressed in neurons and astrocytes in CNS, we used primary cultured oligodendrocytes to test the role of Olig1 K150 acetylation in regulating the Olig1/Id2 interaction. Consistent with earlier studies, the acetylated level of Olig1 K150 increased as oligodendrocytes differentiated and Olig1 acetylation increased in the cytoplasm of differentiated oligodendrocytes in vitro (Fig. 10G). The interaction between Olig1 and Id2 was strongest in the cytoplasm of differentiated oligodendrocytes, which correlated with the higher acetylation of Olig1 in these cells (Fig. 10G). Furthermore, increased Olig1/Id2 interaction was observed when differentiating oligodendrocytes were treated with the general HDAC inhibitor trichostatin A (Fig. 10G), which increased general protein acetylation. These studies demonstrated that Olig1 acetylation at K150 increased the interaction of Olig1 and Id2. The interactions of Olig1 and Id2 would likely facilitate Id2 retention in the cytoplasm, which would repress its inhibitory impact on oligodendrocyte differentiation.

\section{Discussion}

\section{Mechanism of nuclear export of Olig1}

In this study, we first investigated protein sequences that could explain the differences in subcellular localization of Olig1 and Olig2 by identifying two additional NES in Olig1 that are not found in Olig2. NES1 was exactly conserved between Olig1 and Olig2, but Olig1 contained two extra NES, which were stronger than NES1. Intriguingly, ectopic insertion of NES3 of Olig1 into Olig2 was sufficient to drive Olig2 translocation exclusively to the cytoplasm. Therefore, the export signal of NES1 and NES3 together is strong enough to extrude Olig2 from the nucleus. In contrast, despite the presence of both NES1 and NES3, the Olig1dNES2 mutant localized more in the nucleus. Furthermore, even with the three nuclear export sequences, in OPCs, Olig1 is predominantly found in the nucleus, suggesting dynamic regulation of the nuclear export sequences.

Our results demonstrate that Olig1 nuclear export is a finely regulated, multistep process (Fig. 11). The interplay of nuclear retention and nuclear export signals likely determine the subcellular localization of Olig1 developmentally, regulated by the acetylation state of lysine150 in NES1 (lysine139 in mouse). In proliferating OPCs, deacetylated Olig1 is tightly bound to chromatin and its genomic targets. As noted above, the presence of the three NES is insufficient to export Olig1 from the OPC nucleus, suggesting that deacetylated Olig1 may have unique nuclear binding partners that retain it in OPC nuclei. Acetylation of lysine 150 would neutralize the positive charge on this lysine, which could change the protein-binding partner preference of Olig1 or increase the strength of NES1 as a nuclear export signal (Güttler et al., 2010; Regot et al., 2014). As OPCs differentiate and Olig1 is acetylated, it dissociates from the chromatin. Figure 9 shows that this chromatin dissociation preceded, but was not sufficient for its nuclear export, but as OPCs differentiate, Olig1 nuclear-binding proteins may be downregulated or their interaction with acetylated Olig1 may be disrupted, allowing export. In cultured oligodendrocytes and in adult OPCs in vivo, Olig1 chromatin dissociation and nuclear export appear to be uncoupled, with non-chromatin-associated acetylated Olig1 remaining in the 


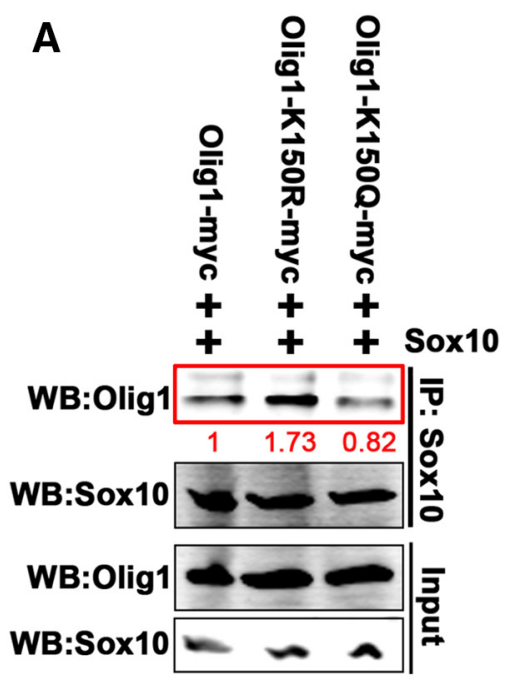

D
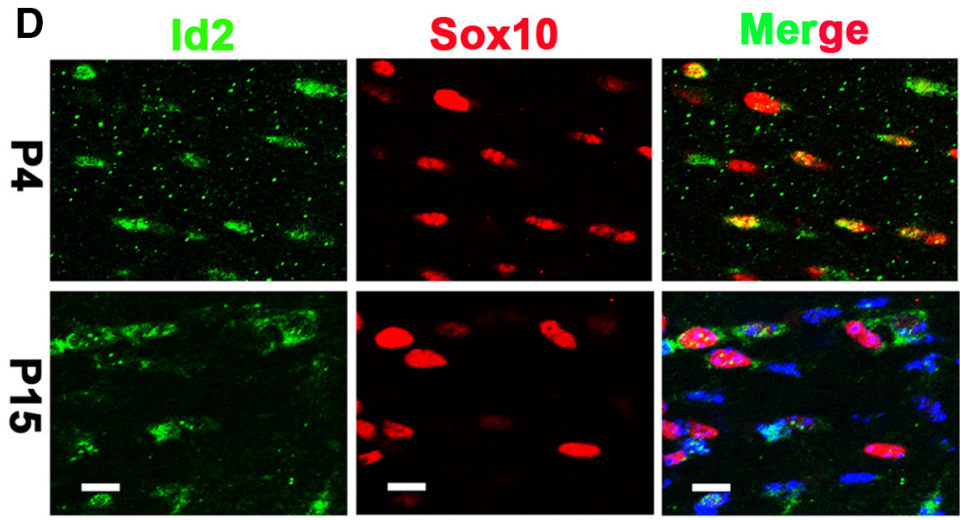

F

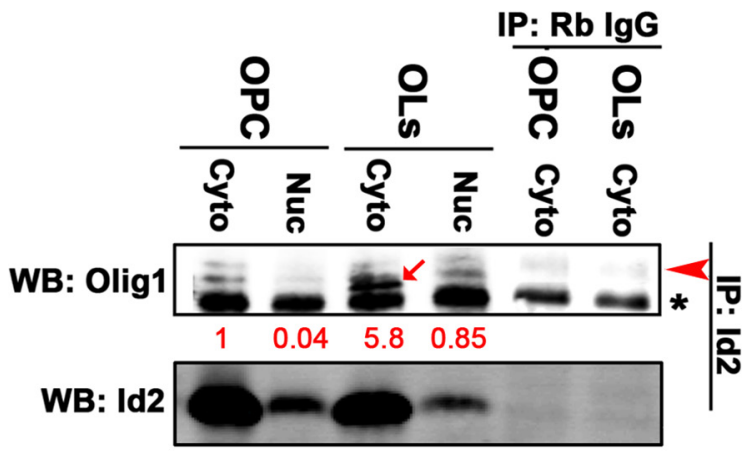

WB: Acetyl-Olig1

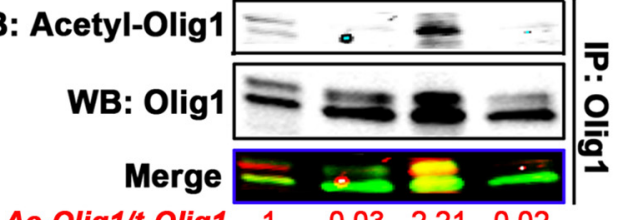

$\begin{array}{lllll}\text { Ac-Olig1/t-Olig1 } & 1 & 0.03 & 2.21 & 0.02\end{array}$

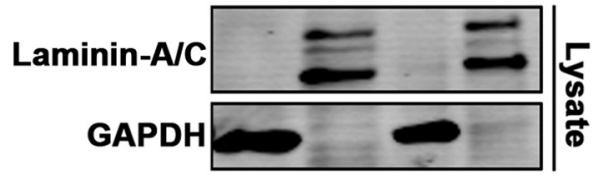

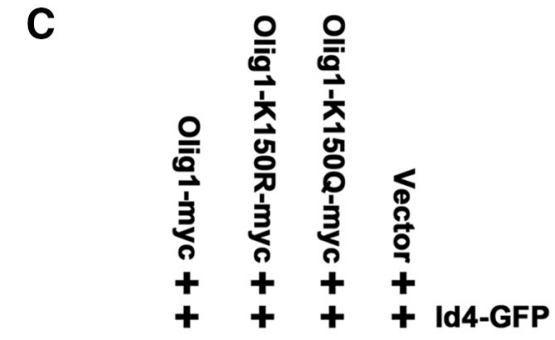

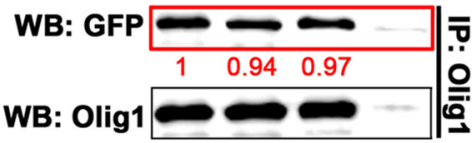

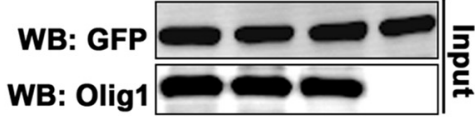

E
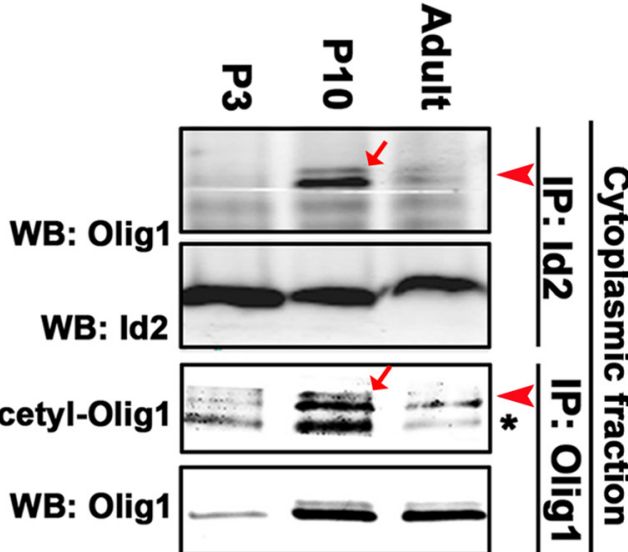

G
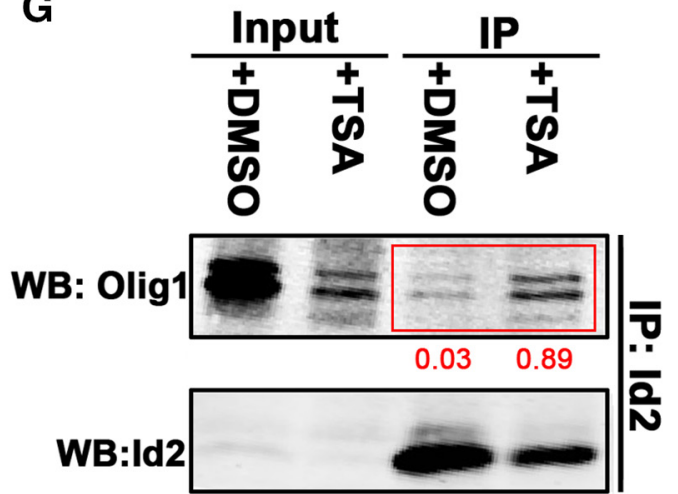

Figure 10. Acetylation of Lysine 150 on 0lig1 increased its binding affinity for Inhibitor of DNA binding 2 (Id2). A-C, Lysine 150 acetylation increased 0 lig1/Id2 interaction. Olig1-myC, deacetylation mimic Olig1-K150R-myc or acetylation mimic Olig1-K150Q-myc were cotransfected with pCMV5-Sox10 (A), Id2-GFP (B), or Id4-GFP (C) into HEK293T cells. Protein interactions were detected by coimmunoprecipitation with the indicated antibodies. Note increased association of deacetylated 0lig1 (0lig1-K150R-myc) with Sox10 ( $\boldsymbol{A}$ ), strong increase in association of acetylated 0lig1 (0lig1-K150Q-myc) with Id2 (B), and no impact of acetylation on association of Olig1 with Id4 (C). Quantification of the ratio of coimmunoprecipitated protein to (Figure legend continues.) 
nucleus. We conclude that, in OPCs, deacetylated Olig1, along with its potential partners, bind chromatin, which serves as a positive regulator of OPC cell cycle exit. As OPCs differentiate, Olig1 is acetylated and dissociates from chromatin, likely reducing its interaction with potential nuclear retention signals and facilitating its subsequent nuclear export, which is important for morphological differentiation of newly formed oligodendrocytes (Fig. 11).

\section{Potential role of Olig1 acetylation in temporospatial control of myelin initiation}

Oligodendrocyte lineage progression and myelin initiation are tightly controlled both temporally and spatially in the developing mouse brain (Trapp et al., 1997; Baumann and Pham-Dinh, 2001). Both extrinsic and intrinsic cues play critical roles in oligodendrocyte differentiation and myelination (for reviews, see Emery, 2010a,b; Wood et al., 2013). However, the mechanism by which oligodendrocytes integrate extracellular signaling with their intrinsic transcriptional program to determine when and where to start myelination is largely unknown. Although Olig1 is clearly important for oligodendrocyte specification and OPC differentiation (Lu et al., 2002; Zhou and Anderson, 2002; Silbereis et al., 2014; Dai et al., 2015), tight temporal control of Olig1 expression and localization as oligodendrocytes initiate myelination implies a potentially negative function of Olig1 when present in the nucleus of myelinating cells. Acetylation of nonhistone proteins is emerging as an important regulator of protein function (Choudhary et al., 2009; Zhao et al., 2010). How the acetylation of Olig1 is temporally regulated during myelinogenesis is still unclear. Preferentially, interaction with HDAC1 and CBP in the developing mouse

\footnotetext{
$\leftarrow$

(Figure legend continued.) total protein input indicated below in red, normalized to control. D, Oligodendrocytes in P4 and P15 mouse corpus callosum were costained with Id2 (green) and Sox10 (red). Note cytoplasmic localization of Id2 at P15. Scale bar, $10 \mu \mathrm{m}$. E, Id 2 interacted with Olig1 at P10 in the cytoplasmic fraction, but not in the nuclear fraction. Mouse subcortical white matter from different postnatal developmental time points was fractionated. Endogenous Id2 was immunoprecipitated from the cytoplasmic or nuclear fraction with Id 2 antibody and 0 lig 1 association was determined by Western blot for 0lig1. Arrowheads, 0lig1; arrow, coimmunoprecipitated 0lig1; asterisks, rabbit lgG. F, The 0lig1/Id2 interaction increased as oligodendrocytes differentiated in vitro. Primary cultured OPCs or differentiated oligodendrocytes were treated with TSA $(500 \mathrm{~nm}$ ) for $10 \mathrm{~h}$, fractionated, and the subcellular fractions were immunoprecipitated with Id2 antibody and detected with 0lig1 antibody (top row) or immunoprecipitated with 0 lig1 antibody and detected with acetyl-0lig1-K150 antibody (middle row). Laminin $\mathrm{A} / \mathrm{C}$ and GAPDH were used as markers for nuclear and cytoplasmic fractions respectively (bottom row). Arrowheads, 0lig1; arrow, coimmunoprecipitated Olig1; asterisks, rabbit lgG. Quantification of the ratio of coimmunoprecipitated 0lig1 to total 0lig1 (top row) and ratio of acetylated 0lig1 to total 0lig1 (middle row) is indicated below in red, normalized to that from cytoplasmic of OPCs. G, Excess acetylation increased the interaction of 0lig1 and Id2. Mouse OPCs were induced to differentiate for $4 \mathrm{~d}$ and treated with DMSO or TSA (100 nm) for $1 \mathrm{~d}$. Cell lysates were immunoprecipitated with anti-Id 2 antibody and detected with 0 lig1 antibody. Quantification of the ratio of coimmunoprecipitated Olig1 to total 0lig1 indicated below in red. All data represent the results from three independent experiments.
}

brain provides one mechanism for regulating Olig1 acetylation at distinct stages. The interaction between Olig1 and CBP or HDAC1 may be regulated by extracellular cues, including signaling from axons. For example, neuronal-activity-induced phosphorylation of $\mathrm{MeCP} 2$ has been shown to serve as a molecular switch to integrate extrinsic signals with intrinsic transcriptional programs in developing brain (Zhou et al., 2006; Tao et al., 2009; Cohen et al., 2011). Differential regulation of Olig1 acetylation in OPCs versus myelinating oligodendrocytes regulates its chromatin association and subcellular translocation. This fine-tuned regulation of Olig1 function at the initiation of myelinating may serve as an important molecular switch to ensure proper temporal-spatial myelination onset.

\section{Nuclear versus cytoplasmic function of Olig1}

In a variety of developing systems, transcription factors important for early cell development are downregulated at later developmental stages (Jessell, 2000; Isshiki et al., 2001; Braun and Gautel, 2011). Therefore, an important question is why Olig1 remains in the cytoplasm as the oligodendrocyte matures. It is possible that Olig1 is important for initial differentiation, but it becomes a negative regulator of later oligodendrocyte differentiation and must be downregulated or translocated. As OPCs begin to differentiate in vivo, they become premyelinating oligodendrocytes before starting to wrap axons (Trapp et al., 1997). Interestingly, Olig1 is greatly reduced in premyelinating oligodendrocytes (Dai et al., 2015), which suggests that sustained nuclear Olig1 may be inhibitory to late oligodendrocyte differentiation and may need to be eliminated in this stage. Consistent with this hypothesis, deacetylated Olig1 in OPC nuclei was associated with 
chromatin and this was important for its nuclear function. However, sustained deacetylated Olig1 nuclear retention inhibited subsequent morphological differentiation (Fig. $5 J$ ). These data support an inhibitory effect of sustained nuclear Olig1 on late oligodendrocyte differentiation during development.

Intriguingly, whereas Olig1 is downregulated in the premyelinating cell, it reappears and is retained in the cytoplasm of myelinating oligodendrocytes. Olig1 expression in the oligodendrocyte cytoplasm long after active myelination is finished suggests its importance in mature oligodendrocytes, but not for myelinogenesis per se (Dai et al., 2015). Nucleocytoplasmic shuttling of transcription factor has long been appreciated as a mechanism that mediates the transcriptional response to the intracellular or extracellular stimuli (Cartwright and Helin, 2000; Gama-Carvalho and Carmo-Fonseca, 2001; Meyer and Vinkemeier, 2004). Dynamic nucleocytoplasmic shuttling provides a mechanism by which transcription factors can quickly turn on or off target gene expression in response to the changing microenvironment. For example, cytoplasmic-localized NF- $\kappa \mathrm{B}, \mathrm{NF}-\mathrm{AT}$, Smad, and STAT family transcription factors instantly translocate to the nucleus to activate their target genes upon cytokine treatment. After removal of the stimuli, they quickly translocate back to the cytoplasm to quench the signaling cascade (Zhu and McKeon, 2000; Herrmann et al., 2007; Hill, 2009; Oeckinghaus and Ghosh, 2009). Nucleocytoplasmic shuttling of transcription factors such as the DNA-damaging sensor P53 (Sharpless and DePinho, 2002), the oxidative stress sensor AP-1 (Yan et al., 1998), and others (Xu and Massagué, 2004) also serves as a mechanism to sense cellular stress, transducing the signal to the nucleus to maintain cellular homeostasis. It is possible that cytoplasmic Olig1 might serve as a sensor for injury to myelinating oligodendrocytes. To further investigate the role of cytoplasmic Olig1 at the molecular level, identification of Olig1interacting proteins in the cytoplasm will be necessary.

\section{Olig1 translocation and remyelination}

Recent studies indicate extensive myelin remodeling in the adult mouse brain, mainly attributed to newly generated oligodendrocytes (Rivers et al., 2008; Young et al., 2013). However, retrospective birth-dating of oligodendrocytes with ${ }^{14} \mathrm{C}$ in human brain indicates that oligodendrocyte number does not change with age and, in fact, very little turnover of oligodendrocytes occurs through life in human white matter. In contrast, comparable analysis of the myelin itself in these postmortem samples indicated that myelin was generated and remodeled throughout life (Yeung et al., 2014). This raises the question of how mature oligodendrocytes remodel myelin. Whether mature oligodendrocytes with cytoplasmic Olig1 are involved in myelin remodeling in the mouse has not been investigated. Newly generated myelin is laid down by existing mature oligodendrocytes in response to learning (Bengtsson et al., 2005; Scholz et al., 2009) and it is intriguing to consider the possibility that movement of cytoplasmic Olig1 back to the nucleus might reactivate myelin production in these cells.

Although Olig1 is required for oligodendrocyte development only in mouse brain (Dai et al., 2015), Olig1 function is essential for remyelination in both spinal cord and brain in several different demyelination models (Arnett et al., 2004; Whitman et al., 2012). The differentiation block in Olig1 null mice during remyelination resembles the finding in MS lesions in which abundant OPCs fail to differentiate (Chang et al., 2000; Chang et al., 2002; Kuhlmann et al., 2008). Considering the role of Olig1 acetylation in regulating its function in oligodendrocyte differentiation, it is possible that Olig1 acetylation is disrupted in OPCs in MS lesions and affects its function in oligodendrocytes. This disruption could result from the altered acetylation patterns seen in MS lesions (Pedre et al., 2011). Therefore, whereas Olig1 is still present in the nuclei in MS lesions (Arnett et al., 2004), its nuclear function may be disrupted by dysregulation of acetylation. Promoting Olig1 function in chronic MS lesions or modulating the Olig1 activity by its acetylation might be meaningful approaches to promote oligodendrocyte differentiation and subsequent myelination in demyelinated lesions.

\section{References}

Arnett HA, Fancy SP, Alberta JA, Zhao C, Plant SR, Kaing S, Raine CS, Rowitch DH, Franklin RJ, Stiles CD (2004) bHLH transcription factor Olig1 is required to repair demyelinated lesions in the CNS. Science 306: 2111-2115. CrossRef Medline

Baumann N, Pham-Dinh D (2001) Biology of oligodendrocyte and myelin in the mammalian central nervous system. Physiol Rev 81:871-927. Medline

Bengtsson SL, Nagy Z, Skare S, Forsman L, Forssberg H, Ullén F (2005) Extensive piano practicing has regionally specific effects on white matter development. Nat Neurosci 8:1148-1150. CrossRef Medline

Braun T, Gautel M (2011) Transcriptional mechanisms regulating skeletal muscle differentiation, growth and homeostasis. Nat Rev Mol Cell Biol 12:349-361. CrossRef Medline

Bujalka H, Koenning M, Jackson S, Perreau VM, Pope B, Hay CM, Mitew S, Hill AF, Lu QR, Wegner M, Srinivasan R, Svaren J, Willingham M, Barres BA, Emery B (2013) MYRF is a membrane-associated transcription factor that autoproteolytically cleaves to directly activate myelin genes. PLoS Biol 11:e1001625. CrossRef Medline

Bullock TH, Moore JK, Fields RD (1984) Evolution of myelin sheaths: both lamprey and hagfish lack myelin. Neurosci Lett 48:145-148. CrossRef Medline

Cartwright P, Helin K (2000) Nucleocytoplasmic shuttling of transcription factors. Cell Mol Life Sci 57:1193-1206. CrossRef Medline

Chang A, Nishiyama A, Peterson J, Prineas J, Trapp BD (2000) NG2positive oligodendrocyte progenitor cells in adult human brain and multiple sclerosis lesions. J Neurosci 20:6404-6412. Medline

Chang A, Tourtellotte WW, Rudick R, Trapp BD (2002) Premyelinating oligodendrocytes in chronic lesions of multiple sclerosis. N Engl J Med 346:165-173. CrossRef Medline

Choudhary C, Kumar C, Gnad F, Nielsen ML, Rehman M, Walther TC, Olsen JV, Mann M (2009) Lysine acetylation targets protein complexes and co-regulates major cellular functions. Science 325:834-840. CrossRef Medline

Cohen S, Gabel HW, Hemberg M, Hutchinson AN, Sadacca LA, Ebert DH, Harmin DA, Greenberg RS, Verdine VK, Zhou Z, Wetsel WC, West AE, Greenberg ME (2011) Genome-wide activity-dependent MeCP2 phosphorylation regulates nervous system development and function. Neuron 72:72-85. CrossRef Medline

Dai J, Bercury KK, Macklin WB (2014) Interaction of mTOR and Erk1/2 signaling to regulate oligodendrocyte differentiation. Glia 62:2096-2109. CrossRef Medline

Dai J, Bercury KK, Ahrendsen JT, Macklin WB (2015) Olig1 function is required for oligodendrocyte differentiation in the mouse brain. J Neurosci 35:4386-4402. CrossRef Medline

di Bari MG, Ciuffini L, Mingardi M, Testi R, Soddu S, Barilà D (2006) c-Abl acetylation by histone acetyltransferases regulates its nuclear-cytoplasmic localization. EMBO Rep 7:727-733. CrossRef Medline

Emery B (2010a) Transcriptional and post-transcriptional control of CNS myelination. Curr Opin Neurobiol 20:601-607. CrossRef Medline

Emery B (2010b) Regulation of oligodendrocyte differentiation and myelination. Science 330:779-782. CrossRef Medline

Franklin RJ, Ffrench-Constant C (2008) Remyelination in the CNS: from biology to therapy. Nat Rev Neurosci 9:839-855. CrossRef Medline

Gama-Carvalho M, Carmo-Fonseca M (2001) The rules and roles of nucleocytoplasmic shuttling proteins. FEBS Lett 498:157-163. CrossRef Medline

Güttler T, Madl T, Neumann P, Deichsel D, Corsini L, Monecke T, Ficner R, Sattler M, Görlich D (2010) NES consensus redefined by structures of 
PKI-type and Rev-type nuclear export signals bound to CRM1. Nat Struct Mol Biol 17:1367-1376. CrossRef Medline

Herrmann A, Vogt M, Mönnigmann M, Clahsen T, Sommer U, Haan S, Poli V, Heinrich PC, Müller-Newen G (2007) Nucleocytoplasmic shuttling of persistently activated STAT3. J Cell Sci 120:3249-3261. CrossRef Medline

Hill CS (2009) Nucleocytoplasmic shuttling of Smad proteins. Cell Res 19: 36-46. CrossRef Medline

Hotchkiss RS, McConnell KW, Bullok K, Davis CG, Chang KC, Schwulst SJ, Dunne JC, Dietz GP, Bähr M, McDunn JE, Karl IE, Wagner TH, Cobb JP, Coopersmith CM, Piwnica-Worms D (2006) TAT-BH4 and TAT$\mathrm{Bcl}-\mathrm{xL}$ peptides protect against sepsis-induced lymphocyte apoptosis in vivo. J Immunol 176:5471-5477. CrossRef Medline

Isshiki T, Pearson B, Holbrook S, Doe CQ (2001) Drosophila neuroblasts sequentially express transcription factors which specify the temporal identity of their neuronal progeny. Cell 106:511-521. CrossRef Medline

Jakovcevski I, Zecevic N (2005) Olig transcription factors are expressed in oligodendrocyte and neuronal cells in human fetal CNS. J Neurosci 25: 10064-10073. CrossRef Medline

Jessell TM (2000) Neuronal specification in the spinal cord: inductive signals and transcriptional codes. Nat Rev Genet 1:20-29. CrossRef Medline

Kitada M, Rowitch DH (2006) Transcription factor co-expression patterns indicate heterogeneity of oligodendroglial subpopulations in adult spinal cord. Glia 54:35-46. CrossRef Medline

Krämer OH, Knauer SK, Greiner G, Jandt E, Reichardt S, Gührs KH, Stauber RH, Böhmer FD, Heinzel T (2009) A phosphorylation-acetylation switch regulates STAT1 signaling. Genes Dev 23:223-235. CrossRef Medline

Kuhlmann T, Miron V, Cuo Q, Wegner C, Antel J, Brück W (2008) Differentiation block of oligodendroglial progenitor cells as a cause for remyelination failure in chronic multiple sclerosis. Brain 131:1749-1758. CrossRef Medline

Kurooka H, Yokota Y (2005) Nucleo-cytoplasmic shuttling of Id2, a negative regulator of basic helix-loop-helix transcription factors. J Biol Chem 280:4313-4320. CrossRef Medline

Li A, Xue Y, Jin C, Wang M, Yao X (2006) Prediction of Nepsilonacetylation on internal lysines implemented in Bayesian discriminant method. Biochem Biophys Res Comm 350:818-824. CrossRef Medline

Li H, Lu Y, Smith HK, Richardson WD (2007) Olig1 and Sox10 interact synergistically to drive myelin basic protein transcription in oligodendrocytes. J Neurosci 27:14375-14382. CrossRef Medline

Lu QR, Sun T, Zhu Z, Ma N, Garcia M, Stiles CD, Rowitch DH (2002) Common developmental requirement for Olig function indicates a motor neuron/oligodendrocyte connection. Cell 109:75-86. CrossRef Medline

MacDonald JI, Kubu CJ, Meakin SO (2004) Nesca, a novel adapter, translocates to the nuclear envelope and regulates neurotrophin-induced neurite outgrowth. J Cell Biol 164:851-862. CrossRef Medline

Meek DW, Anderson CW (2009) Posttranslational modification of p53: cooperative integrators of function. Cold Spring Harb Perspect Biol 1:a000950. Medline

Mei F, Wang H, Liu S, Niu J, Wang L, He Y, Etxeberria A, Chan JR, Xiao L (2013) Stage-specific deletion of Olig2 conveys opposing functions on differentiation and maturation of oligodendrocytes. J Neurosci 33: 8454-8462. CrossRef Medline

Meyer T, Vinkemeier U (2004) Nucleocytoplasmic shuttling of STAT transcription factors. Eur J Biochem 271:4606-4612. CrossRef Medline

Mi YJ, Hou B, Liao QM, Ma Y, Luo Q, Dai YK, Ju G, Jin WL (2012) AminoNogo-A antagonizes reactive oxygen species generation and protects immature primary cortical neurons from oxidative toxicity. Cell Death Differ 19:1175-1186. CrossRef Medline

Nakamura T, Liu YJ, Nakashima H, Umehara H, Inoue K, Matoba S, Tachibana M, Ogura A, Shinkai Y, Nakano T (2012) PGC7 binds histone $\mathrm{H} 3 \mathrm{~K} 9 \mathrm{me} 2$ to protect against conversion of $5 \mathrm{mC}$ to $5 \mathrm{hmC}$ in early embryos. Nature 486:415-419. Medline

Niida H, Katsuno Y, Banerjee B, Hande MP, Nakanishi M (2007) Specific role of Chk1 phosphorylations in cell survival and checkpoint activation. Mol Cell Biol 27:2572-2581. CrossRef Medline

Niu J, Mei F, Wang L, Liu S, Tian Y, Mo W, Li H, Lu QR, Xiao L (2012) Phosphorylated olig1 localizes to the cytosol of oligodendrocytes and promotes membrane expansion and maturation. Glia 60:1427-1436. CrossRef Medline

Oeckinghaus A, Ghosh S (2009) The NF-kappaB family of transcription factors and its regulation. Cold Spring Harb Perspect Biol 1:a000034. Medline

O’Meara RW, Michalski JP, Anderson C, Bhanot K, Rippstein P, Kothary R (2013) Integrin-linked kinase regulates process extension in oligodendrocytes via control of actin cytoskeletal dynamics. J Neurosci 33: 9781-9793. CrossRef Medline

Paes de Faria J, Kessaris N, Andrew P, Richardson WD, Li H (2014) New Olig1 null mice confirm a non-essential role for Olig1 in oligodendrocyte development. BMC Neurosci 15:12. CrossRef Medline

Pedraza CE, Monk R, Lei J, Hao Q, Macklin WB (2008) Production, characterization, and efficient transfection of highly pure oligodendrocyte precursor cultures from mouse embryonic neural progenitors. Glia 56: 1339-1352. CrossRef Medline

Pedre X, Mastronardi F, Brück W, López-Rodas G, Kuhlmann T, Casaccia P (2011) Changed histone acetylation patterns in normal-appearing white matter and early multiple sclerosis lesions. J Neurosci 31:3435-3445. CrossRef Medline

Regot S, Hughey JJ, Bajar BT, Carrasco S, Covert MW (2014) Highsensitivity measurements of multiple kinase activities in live single cells. Cell 157:1724-1734. CrossRef Medline

Rivers LE, Young KM, Rizzi M, Jamen F, Psachoulia K, Wade A, Kessaris N, Richardson WD (2008) PDGFRA/NG2 glia generate myelinating oligodendrocytes and piriform projection neurons in adult mice. Nat Neurosci 11:1392-1401. CrossRef Medline

Samanta J, Kessler JA (2004) Interactions between ID and OLIG proteins mediate the inhibitory effects of BMP4 on oligodendroglial differentiation. Development 131:4131-4142. CrossRef Medline

Scholz J, Klein MC, Behrens TE, Johansen-Berg H (2009) Training induces changes in white-matter architecture. Nat Neurosci 12:1370-1371. CrossRef Medline

Sharpless NE, DePinho RA (2002) p53: good cop/bad cop. Cell 110:9-12. CrossRef Medline

Shen S, Li J, Casaccia-Bonnefil P (2005) Histone modifications affect timing of oligodendrocyte progenitor differentiation in the developing rat brain. J Cell Biol 169:577-589. CrossRef Medline

Silbereis JC, Nobuta H, Tsai HH, Heine VM, McKinsey GL, Meijer DH, Howard MA, Petryniak MA, Potter GB, Alberta JA, Baraban SC, Stiles CD, Rubenstein JL, Rowitch DH (2014) Olig1 function is required to repress $\mathrm{dlx} 1 / 2$ and interneuron production in mammalian brain. Neuron 81:574-587. CrossRef Medline

Soane L, Fiskum G (2005) TAT-mediated endocytotic delivery of the loop deletion $\mathrm{Bcl}-2$ protein protects neurons against cell death. J Neurochem 95:230-243. CrossRef Medline

Tao J, Hu K, Chang Q, Wu H, Sherman NE, Martinowich K, Klose RJ, Schanen C, Jaenisch R, Wang W, Sun YE (2009) Phosphorylation of $\mathrm{MeCP} 2$ at Serine 80 regulates its chromatin association and neurological function. Proc Natl Acad Sci U S A 106:4882-4887. CrossRef Medline

Trapp BD, Nave KA (2008) Multiple sclerosis: an immune or neurodegenerative disorder? Annu Rev Neurosci 31:247-269. CrossRef Medline

Trapp BD, Nishiyama A, Cheng D, Macklin W (1997) Differentiation and death of premyelinating oligodendrocytes in developing rodent brain. J Cell Biol 137:459-468. CrossRef Medline

Wang S, Sdrulla A, Johnson JE, Yokota Y, Barres BA (2001) A role for the helix-loop-helix protein Id 2 in the control of oligodendrocyte development. Neuron 29:603-614. CrossRef Medline

Whitman LM, Blanc CA, Schaumburg CS, Rowitch DH, Lane TE (2012) Olig1 function is required for remyelination potential of transplanted neural progenitor cells in a model of viral-induced demyelination. Exp Neurol 235:380-387. CrossRef Medline

Wolswijk G (1998) Oligodendrocyte regeneration in the adult rodent CNS and the failure of this process in multiple sclerosis. Prog Brain Res 117: 233-247. CrossRef Medline

Wolswijk G (2000) Oligodendrocyte survival, loss and birth in lesions of chronic-stage multiple sclerosis. Brain 123:105-115. CrossRef Medline

Wood TL, Bercury KK, Cifelli SE, Mursch LE, Min J, Dai J, Macklin WB (2013) mTOR: a link from the extracellular milieu to transcriptional regulation of oligodendrocyte development. ASN Neurol 5:e00108. CrossRef Medline

Xin M, Yue T, Ma Z, Wu FF, Gow A, Lu QR (2005) Myelinogenesis and axonal recognition by oligodendrocytes in brain are uncoupled in Olig1null mice. J Neurosci 25:1354-1365. CrossRef Medline 
Xu L, Massagué J (2004) Nucleocytoplasmic shuttling of signal transducers. Nat Rev Mol Cell Biol 5:209-219. Medline

Yan C, Lee LH, Davis LI (1998) Crmlp mediates regulated nuclear export of a yeast AP-1-like transcription factor. EMBO J 17:7416-7429. CrossRef Medline

Yeung MS, Zdunek S, Bergmann O, Bernard S, Salehpour M, Alkass K, Perl S, Tisdale J, Possnert G, Brundin L, Druid H, Frisén J (2014) Dynamics of oligodendrocyte generation and myelination in the human brain. Cell 159:766-774. CrossRef Medline

Young KM, Psachoulia K, Tripathi RB, Dunn SJ, Cossell L, Attwell D, Tohyama K, Richardson WD (2013) Oligodendrocyte dynamics in the healthy adult CNS: evidence for myelin remodeling. Neuron 77:873-885. CrossRef Medline

Zhao S, Xu W, Jiang W, Yu W, Lin Y, Zhang T, Yao J, Zhou L, Zeng Y, Li H,
Li Y, Shi J, An W, Hancock SM, He F, Qin L, Chin J, Yang P, Chen X, Lei Q, et al. (2010) Regulation of cellular metabolism by protein lysine acetylation. Science 327:1000-1004. CrossRef Medline

Zhou Q, Anderson DJ (2002) The bHLH transcription factors OLIG2 and OLIG1 couple neuronal and glial subtype specification. Cell 109:61-73. CrossRef Medline

Zhou Z, Hong EJ, Cohen S, Zhao WN, Ho HY, Schmidt L, Chen WG, Lin Y, Savner E, Griffith EC, Hu L, Steen JA, Weitz CJ, Greenberg ME (2006) Brain-specific phosphorylation of $\mathrm{MeCP} 2$ regulates activity-dependent Bdnf transcription, dendritic growth, and spine maturation. Neuron 52: 255-269. CrossRef Medline

Zhu J, McKeon F (2000) Nucleocytoplasmic shuttling and the control of NF-AT signaling. Cell Mol Life Sci 57:411-420. CrossRef Medline 